NISTIR 8265

\title{
A New Method for Tensile Testing UHMMPE Single Fibers at High Temperatures and Strain-Rates
}

Donald R. Jenket

Amy E. Engelbrecht-Wiggans

Amanda L. Forster

Mohamad Al-Sheikhly

This publication is available free of charge from:

https://doi.org/10.6028/NIST.IR.8265

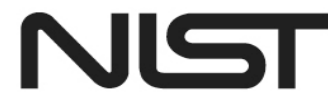

National Institute of Standards and Technology U.S. Department of Commerce 


\title{
A New Method for Tensile Testing UHMMPE Single Fibers at High Temperatures and Strain-Rates
}

\author{
Donald R. Jenket \\ Amy E. Engelbrecht-Wiggans \\ Amanda L. Forster \\ Materials Measurement Science Division \\ Material Measurement Laboratory \\ Mohamad Al-Sheikhly \\ Department of Materials Science and Engineering \\ University of Maryland, College Park
}

This publication is available free of charge from:

https://doi.org/10.6028/NIST.IR.8265

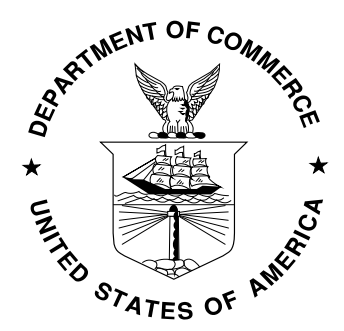

U.S. Department of Commerce Wilbur L. Ross, Jr., Secretary

National Institute of Standards and Technology Walter Copan, NIST Director and Undersecretary of Commerce for Standards and Technology 
Certain commercial entities, equipment, or materials may be identified in this document in order to describe an experimental procedure or concept adequately. Such identification is not intended to imply recommendation or endorsement by the National Institute of Standards and Technology, nor is it intended to imply that the entities, materials, or equipment are necessarily the best available for the purpose.

National Institute of Standards and Technology Interagency or Internal Report 8265 Natl. Inst. Stand. Technol. Interag. Intern. Rep. 8265, 29 pages (August 2019)

This publication is available free of charge from: https://doi.org/10.6028/NIST.IR.8265 


\begin{abstract}
The performance of body armor made of ultra-high molecular weight polyethylene (UHMMPE) is dependent on the tensile strength of UHMMPE fibers. UHMMPE is known to exhibit different mechanical properties when tested at different strain rates and different temperatures. The high tensile strength and low surface energy make it difficult to securely grip single fibers while testing without any slippage. Consequently, making accurate measurements of the tensile strength of this material is challenging. Efforts to simultaneously interrogate strain-rate and temperature conditions have been complicated by the difficulty in gripping the fiber, and in consistently heating a small $(\approx 15 \mu$ m diameter $)$ fiber. In this paper, a method is described for tensile testing single UHMMPE fibers at high rates and high temperatures, focusing on an innovative clamp design and a specialized single fiber heater that can be coupled to traditional tools for measuring mechanical properties of fibers. Metrics of success for the single fiber clamps are described based on the percentage of failures observed at the jaw grips and the strain to failure.
\end{abstract}

\title{
Key words
}

Grips, rate effects, single fiber, tensile testing, thermal effects, ultra-high molar mass polyethylene, UHMMPE, ultra-high molecular weight polyethylene, UHMWPE 


\section{Table of Contents}

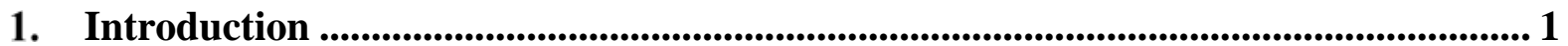

2. Experimental Methods ............................................................................................................ 1

2.1. Specimen Preparation..................................................................................... 1

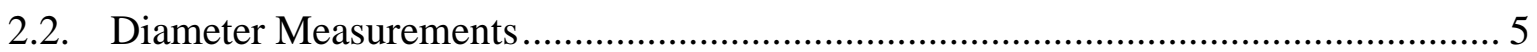

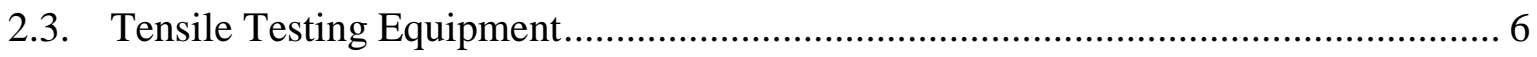

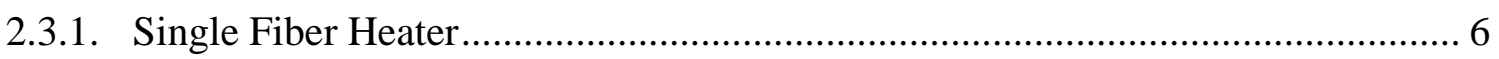

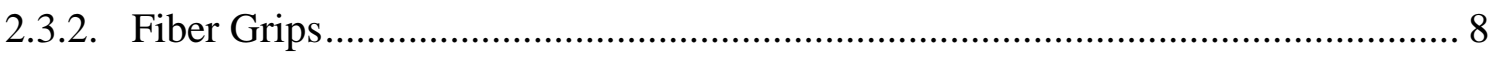

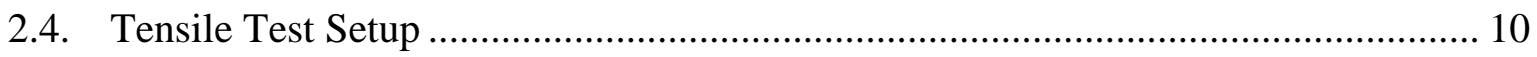

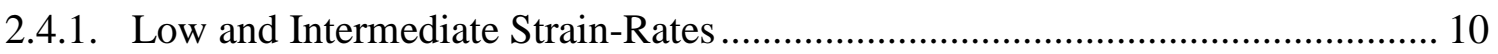

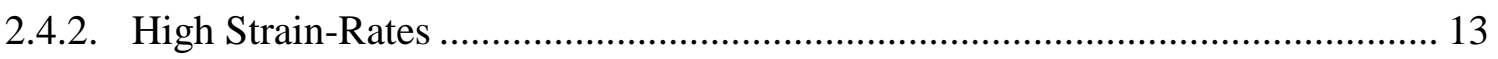

3. Selected Results.............................................................................................................. 17

3.1. Categorization and Number of Fiber Tests ............................................................ 17

3.2. Percentage of failures in gauge region ................................................................ 18

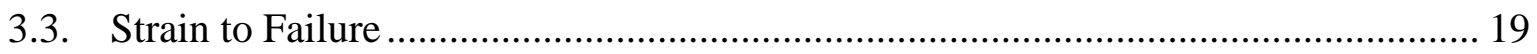

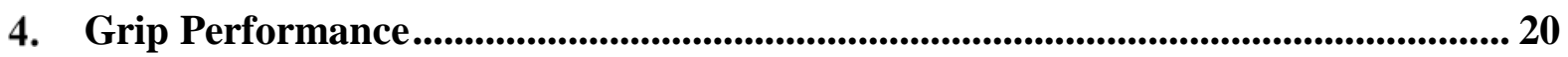

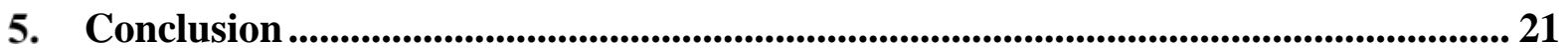

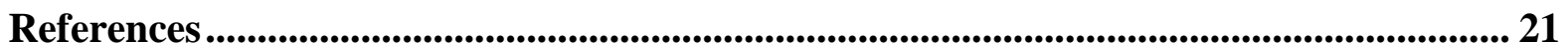

\section{List of Tables}

Table 1. Key instrument test parameters for the Bose Electroforce 3100 Universal Testing Machine.

Table 2. The summary of the Student's t-tests for the correction experiments at $500 \mathrm{~s}^{-1}$. The total number of tests considered are. 16

Table 3. The number of fibers tests, failures at the grip interface (given in parentheses), and non-failures (given on the left of a slash) in each testing combination for the temperaturestrain-rate tensile study. A total of 59 fiber specimens were tested in this study. The highlighted region depicts the non-failure surface.

Table 4. The number of grip interface failures observed for the 59 tensile tests, categorized by strain-rate. The last row shows the overall success if the non-failures are removed from the calculations.

Table 5. The number of grip interface failures and success rates observed for the $20^{\circ} \mathrm{C}$ data set including retests and fibers used for non-tensile purposes. The $5^{\text {th }}$ and $6^{\text {th }}$ columns show the number and success rates if the higher than average failure strength fibers are removed from the calculations. The last column shows the grip success rates for Sanborn, et al. [11] for strain-rates conducted in their study.....

Table 6. Comparison of the uncorrected and corrected average strain to failure values and associated standard deviations observed in this study at $20^{\circ} \mathrm{C}$ and those by Sanborn, et al. 
[11] Sandborn's experiments utilized 10 specimens per strain rate. The number of specimens used in our study can be found in Table 3.

Table 7. Average strain to failure values with \pm one standard deviation , with the number of specimens given in Table 3. The highlighted region indicates non-failure behavior. The $10^{-3}$ $\mathrm{s}^{-1}$ strain-rate at $75^{\circ} \mathrm{C}$ resulted in only one of the five tensile tests failing and therefore lacks a standard deviation.

\section{List of Figures}

Fig. 1. Pictures of the spool of UHMMPE 1760 dtex yarn used in this study, where (a) was taken after the $400 \mathrm{~m}$ of yarn was removed from the outer surface of the spool, (b) shows the top surface of the spool showing contamination from particles and discoloration from handling, and (c) shows the middle surface of the spool showing no contamination. Specimens were created from fibers drawn in this region of the spool depicted in (c)............ 2 Fig. 2. (a) An image of the taped yarn. (b) The cut tape-clamped yarn maintaining fiber alignment. The top yarn is attached to the spool and is used for extracting samples. The bottom yarn is discarded .............................................................................................. 2

Fig. 3. (a) An image of the tape-clasped yarn on the self-healing mat and the splayed end. (b) A taped single fiber amidst the splayed yarn.

Fig. 4. The process of making a tape-capstan, starting with (a) a single fiber on a piece of tape, then in (b) the tape is repeatedly folded over approximately $1 \mathrm{~mm}$, and then in (c) the completed tape-capstan securely holding the fiber for specimen preparation. 3

Fig. 5. (a) The fiber template illustrating the dimensions used in mm, with a single fiber specimen showing the glued, gripped, and gauge areas. The white region is the inner rectangle that is cut away. (b) Single fiber specimen 25-8 adhered to a template. The lines on the template indicate the $10 \mathrm{~mm}$ gauge length and can be used for reference in post-failure analysis.

Fig. 6. (a) An image of the adhesive-curing phase of the first batch of 18 fibers making 324 specimens. (b) A closer image of the adhesive-curing phase showing the single fiber specimens along the templates.

Fig. 7. (a) An image of the diameter measurement process with the fiber in focus before the horizontal graticule lines are moved. (b) A fiber diameter measurement showing the top of each horizontal graticule line touching an edge of the fiber.

Fig. 8. (a) The single fiber heater in the open position. One cartridge heater is shown unmounted for reference. (b) The single fiber heater on the supporting stand with polytetrafluroethylene spacers.

Fig. 9. (a) The closed single fiber heater with the calibration wire thermocouple installed in the fiber channel. (b) The top view of the setup displaying the U-shaped wire thermocouple mount and $x-y-z$ translation stage setups. White arrows indicate the thermocouple, and fiber grips are not installed in this photograph........................................................................ 7

Fig. 10. Magnified schematics of (a) the grip bottom displaying the fiber, polycarbonate " $T$ ", guide posts, screw holes, and template area, and (b) the closed grip showing the top in position without the $0-80$ screws.

Fig. 11. The Bose 3100 fiber gripping area including grips, heater, standoff assembly, and force sensor. 
Fig. 12. (a) A templated fiber specimen placed on top of the open grips (removable grip tops not in place) and aligned. (b) A gripped fiber before the template is cut, with removable grip tops in place. (c) A gripped fiber with the template cut. (d) A fiber specimen gripped in the closed heater channel and ready for testing.

Fig. 13. The Bose 3100 fiber testing area including Bose 3100, testing area, stereo microscope, electric torque driver, heater assembly, digital thermometer and voltage controller. 13

Fig. 14. An image of the testing area of the fiber-SHTB showing the measurement devices including the piezoelectric load cell, thermal standoff assembly, closed grips with fiber sample, heater bottom half, and optical setup for measuring displacement

Fig. 15. The displacement calibration setup showing the linear translation stage and driving plate. Also shown in this image are the strain gauges and Wheatstone bridge with variable resistor

Fig. 16. An example of the linear fitting of a voltage-displacement data. The black dots are the measured data and the red line is the linear fit. The line equation and $\mathrm{R}^{2}$ values are also displayed.

Fig. 17. Whisker plots for the correction showing a comparison between (a) peak force, (b) average fiber diameter, and (c) the pre-tension force or starting force. In a whisker plot the ends of the box are the upper and lower quartiles, while the whiskers extend to the extreme values. 


\section{Introduction}

Ultra-high molar mass polyethylene (UHMMPE) single fibers exhibit superior strength in the axial direction of the fiber due to their highly aligned crystalline structure. Armor manufacturers have utilized the exceptional strength of these materials and have created advanced armor designs to withstand both handgun and rifle threats. However, the strength of commercial UHMMPE fibers is still well below theoretical calculations due to a variety of manufacturing challenges, such as the population of defects, dislocations, and chain ends in the polymer resin from which the fibers are made [1]. Understanding the performance of UHMMPE fibers at a variety of temperatures and strain rates that are representative of their use condition in ballistic-resistant body armor is imperative to determining how to improve armor materials and designs for the future.

Securely gripping UHMMPE single fibers for tensile testing is challenging because they have a low surface energy [2] combined with a high tensile strength [3, 4]. Capstan methods have been used to learn about failure stresses [5], but the failure strains from this method can be questionable due to the difficulties in determining an accurate gauge length within the capstan $[3,6]$. Direct gluing fibers to cardboard templates has shown limited success and is dependent on fiber diameter $[7,8]$. A combination of adhesive and pressing between rubber tabs has had reported success, however, only a small numbers of tests were performed [4]. For poly(p-phenylene terephthalamide), commonly known as aramid, fibers, grips that minimize slippage have been developed to directly grip fibers between two tabs of poly(methyl methacrylate) $[9,10]$, and the same design using polycarbonate tabs has shown to be successful for UHMMPE single fibers [11]. However, the gripping tabs in these designs are recessed from the grip edge, which prevents access to the gauge length of the fiber for conducting temperature-dependence experiments. To investigate the simultaneous effects of strain-rate and temperature on the mechanical properties of UHMMPE single fibers, specialized grips must be designed to both grip the fibers securely and accommodate the use of a fiber heater. These grips must accommodate both a quasi-static test frame as well as a fiber-Split-Hopkinson Tension Bar (fiber-SHTB) for high strain-rates. This report describes a set of grips that meet these requirements and describes the metrics that were used to evaluate their performance.

\section{Experimental Methods}

\subsection{Specimen Preparation}

All single fiber specimens used in this study were prepared from the same spool of commercially-available UHMMPE $1.76 \times 10^{-4} \mathrm{~kg} / \mathrm{m}$ yarn. The spool has been protected from exposure to light and maintained under dry, ambient laboratory conditions of approximately $22{ }^{\circ} \mathrm{C}$ and less than $20 \%$ relative humidity, but not sealed in an air-tight container. To minimize effects from contamination on the surface of the spool, approximately $400 \mathrm{~m}$ of yarn was removed to reveal yarn that was not directly exposed to the laboratory atmospheric environment. Yarns were selected from the center of the spool to avoid any contamination from table surfaces near the spool edges, as shown in Fig. 1. 


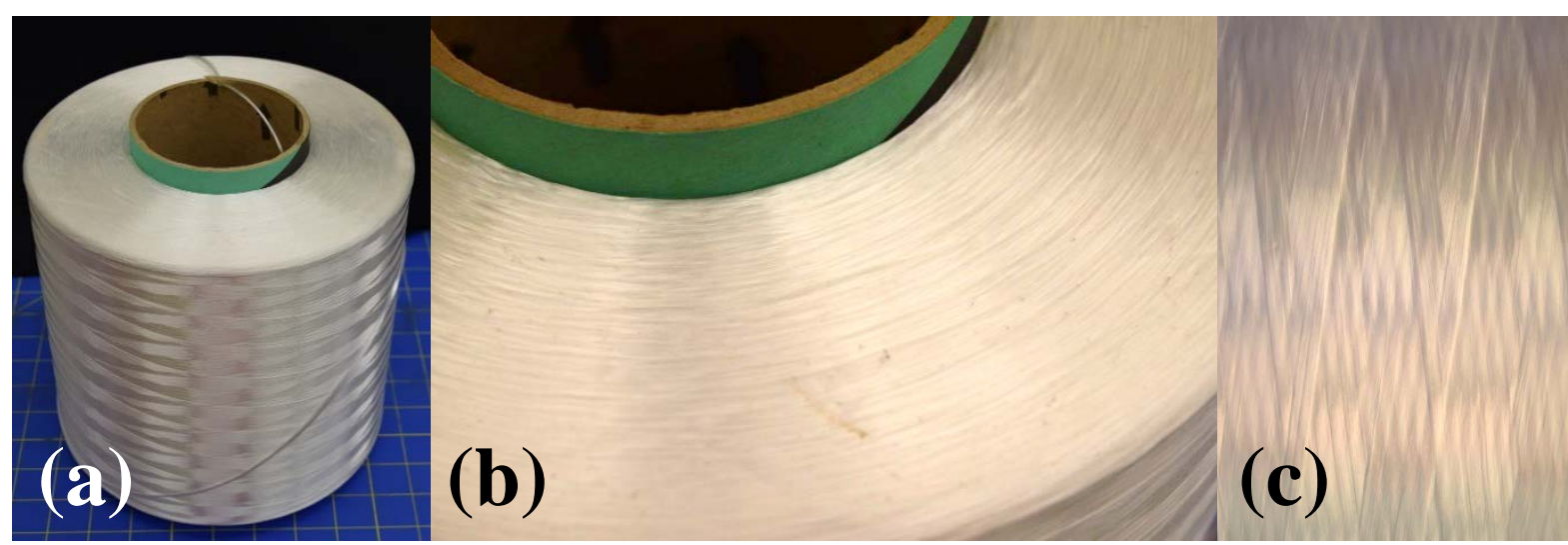

Fig. 1. Pictures of the spool of UHMMPE 1760 dtex yarn used in this study, where (a) was taken after the $400 \mathrm{~m}$ of yarn was removed from the outer surface of the spool, (b) shows the top surface of the spool showing contamination from particles and discoloration from handling, and (c) shows the middle surface of the spool showing no contamination. Specimens were created from fibers drawn in this region of the spool depicted in (c).

Maintaining fiber alignment within the yarn is crucial to prevent fiber entanglements and to allow the extraction of single fibers [11]. For this reason, the yarn was clasped with tape at its cut locations to prevent the bulk yarn from splaying while not hindering the separation of single fibers from the yarn. The yarn was cut through the tape, as shown in Fig. 2. All cutting was performed with ceramic scissors. .
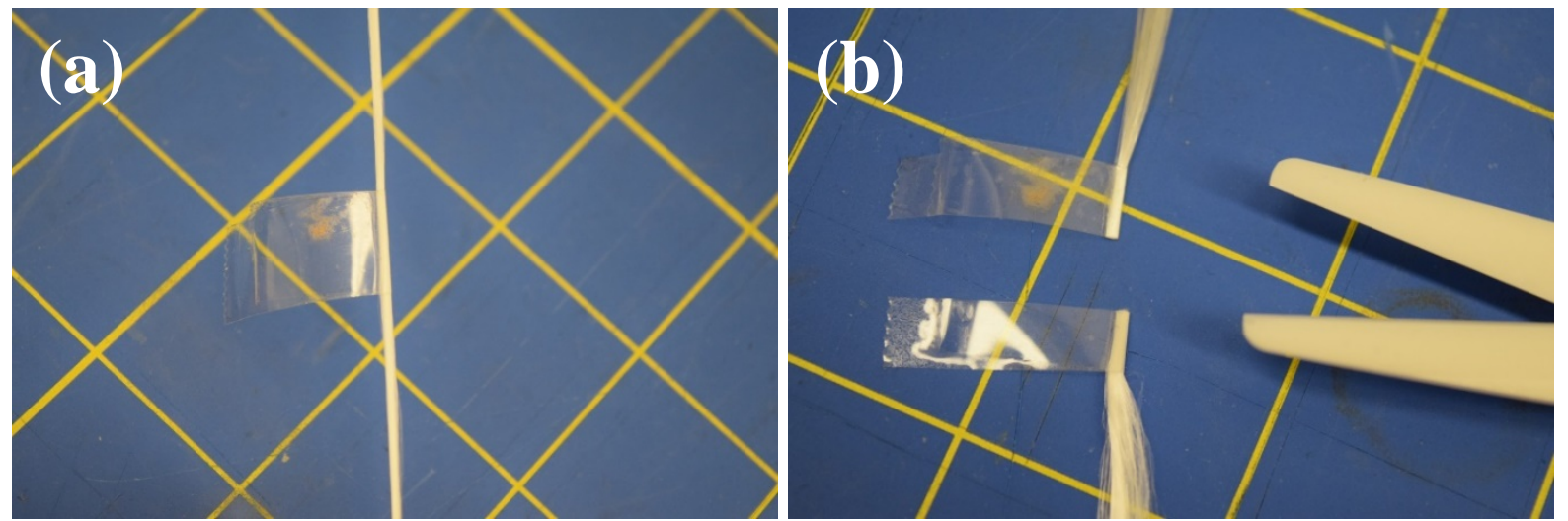

Fig. 2. (a) An image of the taped yarn. (b) The cut tape-clamped yarn maintaining fiber alignment. The top yarn is attached to the spool and is used for extracting samples. The bottom yarn is discarded 

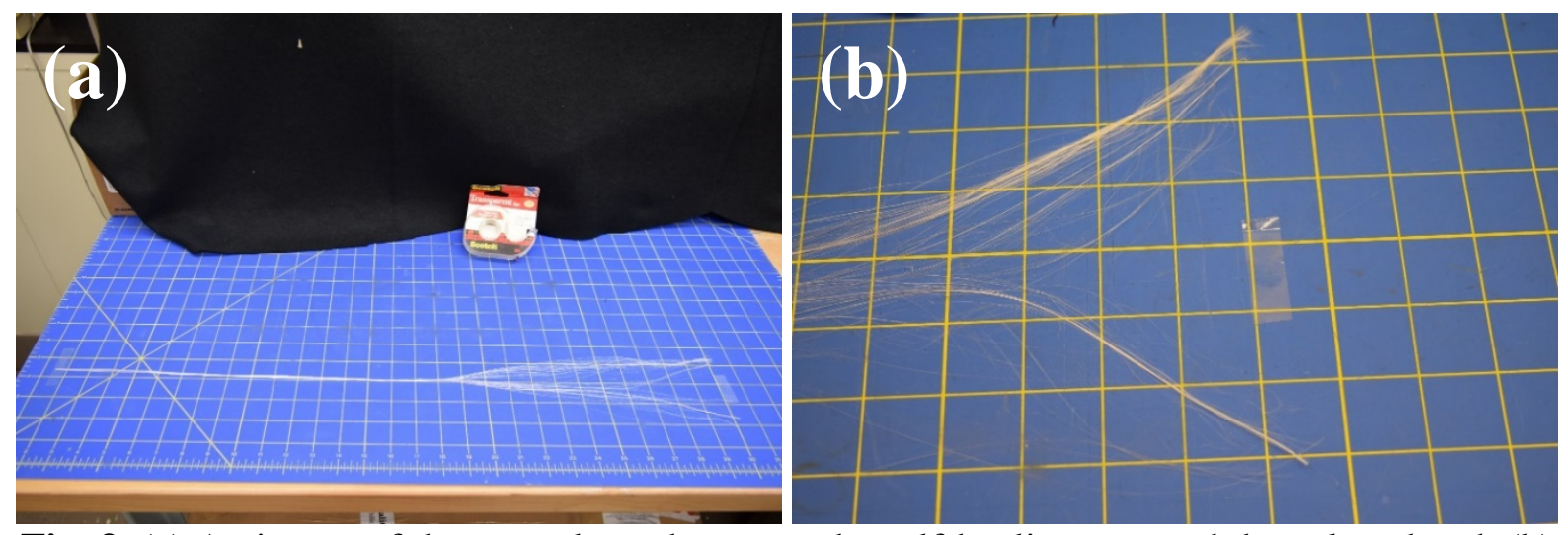

Fig. 3. (a) An image of the tape-clasped yarn on the self-healing mat and the splayed end. (b) A taped single fiber amidst the splayed yarn.

Yarn lengths of approximately $1 \mathrm{~m}$ were slowly unwound from the spool while being maintained under slight tension to prevent contact with any surrounding surfaces. The second end of the yarn was then tape-clamped and cut as described previously. The yarn samples that were taped on both ends were moved to an ethanol-rinsed self-healing cutting mat. One taped end of the yarn sample was then taped to the cutting mat and the other taped end was cut away to allow separation of the individual fibers. The now non-taped end of the yarn was carefully spread to expose single fibers, shown in Fig 3 (a). A single fiber was identified, and its end was manually held in place while it was separated from the surrounding fibers. A piece of tape was then placed directly on the single fiber end, shown in Fig. 3 (b). The tape was then rolled back on itself approximately every $1 \mathrm{~mm}$ to resemble a tape-capstan, as shown in Fig. 4.
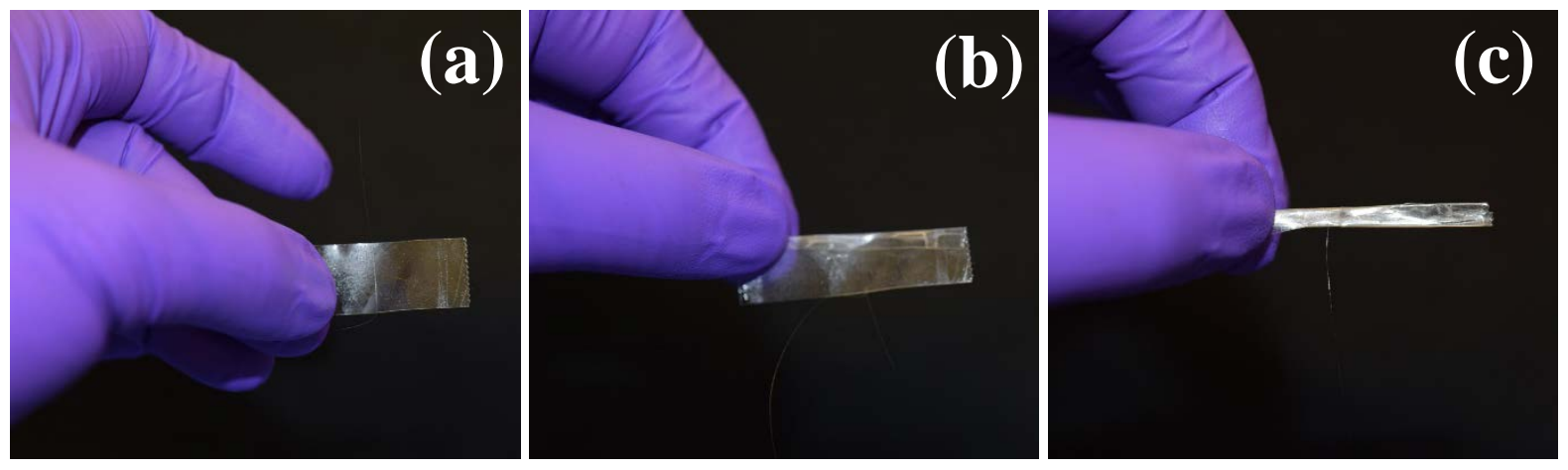

Fig. 4. The process of making a tape-capstan, starting with (a) a single fiber on a piece of tape, then in (b) the tape is repeatedly folded over approximately $1 \mathrm{~mm}$, and then in (c) the completed tape-capstan securely holding the fiber for specimen preparation.

A small tensile force was manually applied to the tape-capstan end of the fiber to gently extract the single fiber sample from the tape-clamp on the other end. Careful attention was paid to avoid tangling of the fibers during separation from the bulk yarn. If the level of tangling caused permanent deformation in the fiber, which was visible to the user as large kinks or periodic curvatures along the fiber length, the fiber sample was considered damaged during extraction and discarded. It was observed that from each yarn sample, approximately 5 to 10 single fiber samples could be extracted before the fiber entanglement became 
unmanageable to extract any additional single fibers without damage. In total, 57 single fiber samples were prepared using this method.

A gauge length of $10 \mathrm{~mm}$ was selected for the experiments [6]. Hollow rectangular templates were created to keep the fiber aligned and stationary for directly-gripped tensile experiments. The specifications for the rectangle templates are shown in Fig. 5 (a). Transparency sheets were used as the template material due to their higher stiffness as compared to paper stock. The stiffer substrate provided a more stable template for transporting, storing, and directly gripping the fiber specimens. The template outlines were first drawn by hand and later templates were laser-printed from a file created using commercially-available design software to allow repeatable control of the template dimensions. The outer dimensions of the template were $31 \mathrm{~mm}$ by $11.5 \mathrm{~mm}$. An inner rectangle with dimensions $24 \mathrm{~mm}$ by $6.5 \mathrm{~mm}$ was cut away using a craft knife or razor blade, making the template dimensions $2.5 \mathrm{~mm}$ wide along the long axis and $3.5 \mathrm{~mm}$ wide along the short axis. The $24 \mathrm{~mm}$ rectangle provided $10 \mathrm{~mm}$ of sample gauge length and two $7 \mathrm{~mm}$ gripping areas on the ends. To maximize the number of specimens per nominally $216 \mathrm{~mm}$ by $280 \mathrm{~mm}$ ( 8.5 in by $11 \mathrm{in}$ ) sheet of template material, the template was repeated 9 times along the long axis and 18 times along short axis. All templates were marked to show the $10 \mathrm{~mm}$ gauge for post-failure analysis. The template was cut along the long edge to create strips that were nine specimens long. Two strips were then taped on the cutting mat with their short edges touching to create an 18-specimen-long strip. The templates were labeled with the fiber and sample numbers for a given fiber. A single fiber sample, i.e. an approximately $1 \mathrm{~m}$ long single fiber of which 18 specimens are created, was taped to one end of the strip and then laid across the center of the 18 hollowed rectangles, one rectangle for each of the 18 templates comprising the strip. A plastic mini spring clamp was placed on the free taped end of the fiber sample and hung off the edge of the surface to keep the fiber sample taught. The clamps have an average mass of $4.20 \mathrm{~g}$ with a standard deviation of $0.025 \mathrm{~g}$, as determined from 10 measurements. Neglecting possible friction at the table edge, the pre-tension force on the fibers during preparation was nominally $41.3 \mathrm{mN}$. (For reference, the fibers fail at room temperature at approximately $1 \mathrm{~N}$ of force.) Each fiber specimen was then glued to both ends of its respective template using a high viscosity cyanoacrylate adhesive, 4g Ultra Gel Control Super Glue (model 1363589). An image of a batch of fibers in the adhesive-curing phase is shown in Fig. 6. The ends of each fiber specimen were glued with independent small adhesive drops between adjacent templates to prevent cutting through a single large adhesive drop (which can strain the fiber specimen). The adhesive was selected after performing a thorough investigation of various adhesives. After at least 24 hours of curing, the fiber samples were cut along the short axis to separate 18 individual fiber specimens. A $10 \mathrm{~mm}$ single fiber specimen on a template is shown in Fig. 5 (b). 


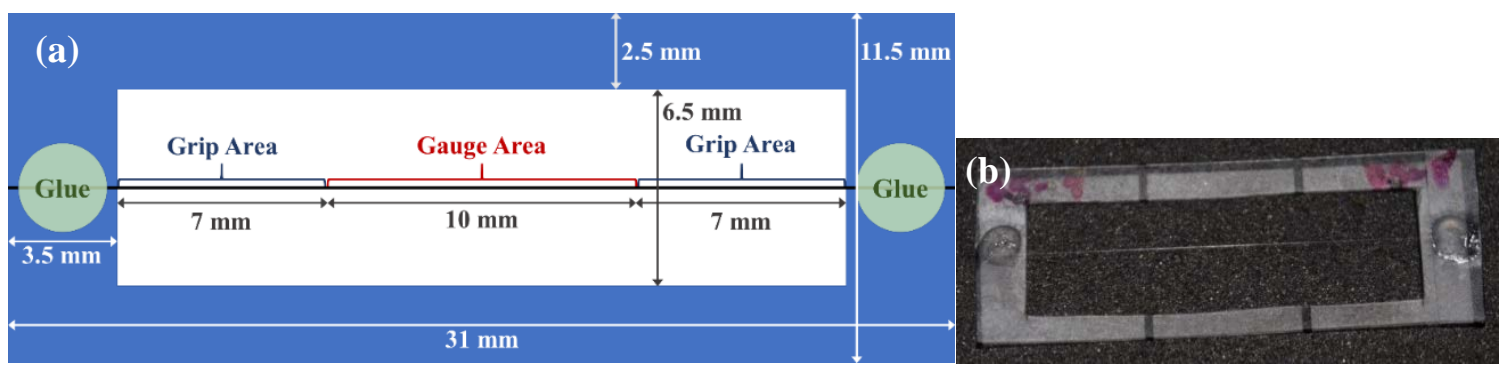

Fig. 5. (a) The fiber template illustrating the dimensions used in mm, with a single fiber specimen showing the glued, gripped, and gauge areas. The white region is the inner rectangle that is cut away. (b) Single fiber specimen 25-8 adhered to a template. The lines on the template indicate the $10 \mathrm{~mm}$ gauge length and can be used for reference in post-failure analysis.
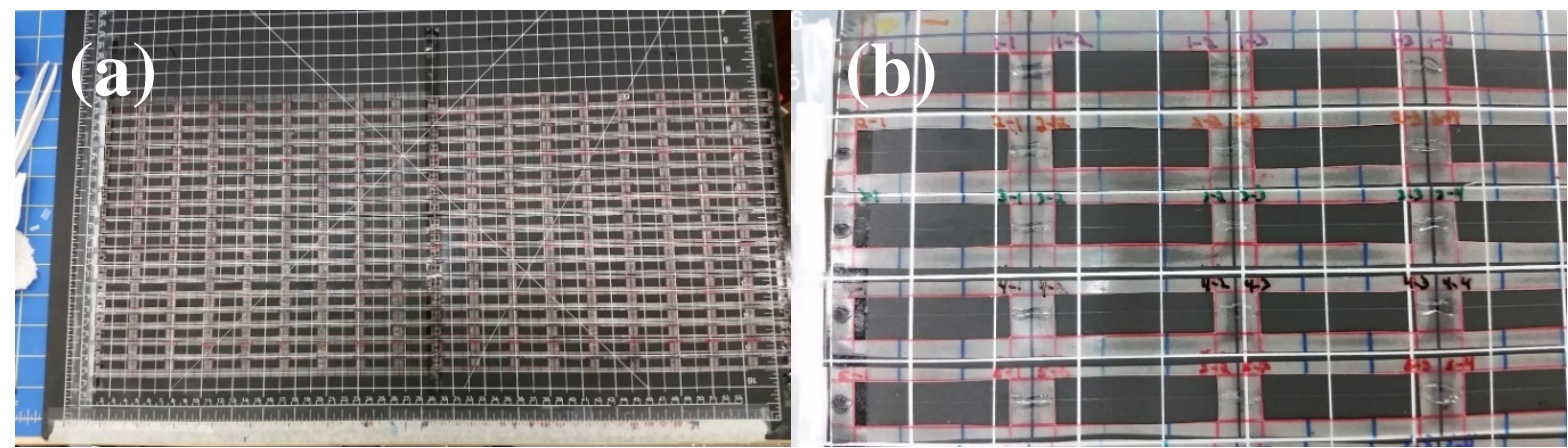

Fig. 6. (a) An image of the adhesive-curing phase of the first batch of 18 fibers making 324 specimens. (b) A closer image of the adhesive-curing phase showing the single fiber specimens along the templates.

The specimens from a single 18-specimen-long fiber sample showed similar diameters between specimens. For this reason, sets of fiber samples that were selected for the same temperature-strain-rate testing combination did not contain two specimens from the same 18specimen-long fiber sample to avoid the effects of fiber diameters biasing the results.

\subsection{Diameter Measurements}

Fiber diameters were measured top down using a Nikon OptiPhot-POL Polarizing Microscope with a 60x magnification lens and a Boeckeler VIA-100 Imaging System with a 3.1x magnification microscope camera. The image was displayed on a Sony Trinitron super fine pitch monitor and the VIA-100 controller was used to translate two horizontal lines. The distance between the lines (in $\mu \mathrm{m}$ ) was displayed on the monitor (Fig. 7). The translation of the horizontal lines was incremented at approximately $0.11 \mu \mathrm{m}$ or $0.12 \mu \mathrm{m}$. This controller is limited to measuring diameters between $15.8 \mu \mathrm{m}$ to $21.02 \mu \mathrm{m}$, with a nominal resolution of $0.11 \mu \mathrm{m}$. The templated fiber specimen was placed so that one end of the gauge length at a $10 \mathrm{~mm}$ marker line was centered on the light source and in the microscope image. The microscope camera was rotated to align the fiber length with the VIA-100 graticule lines. The fiber was brought into focus and the side-view diameter was measured by aligning the top edge of the bottom horizontal graticule line with the bottom edge of the fiber and by aligning the top edge of the top horizontal graticule line with the top edge of the fiber, as 
shown in Fig. 7 (a) and 7 (b). The viewing stage was connected to an $x-y$ translator and the diameter measurement was repeated four more times along the $10 \mathrm{~mm}$ gauge length, with a nominal spacing between diameter measurements of $2.5 \mathrm{~mm}$ to give a total of five diameter measurements per fiber specimen. The arithmetic mean of the five diameter measurements was calculated as the average diameter, $d_{\mathrm{avg}}$, and the minimum of the five measurements was recorded as the diameter minimum, $d_{\min }$.
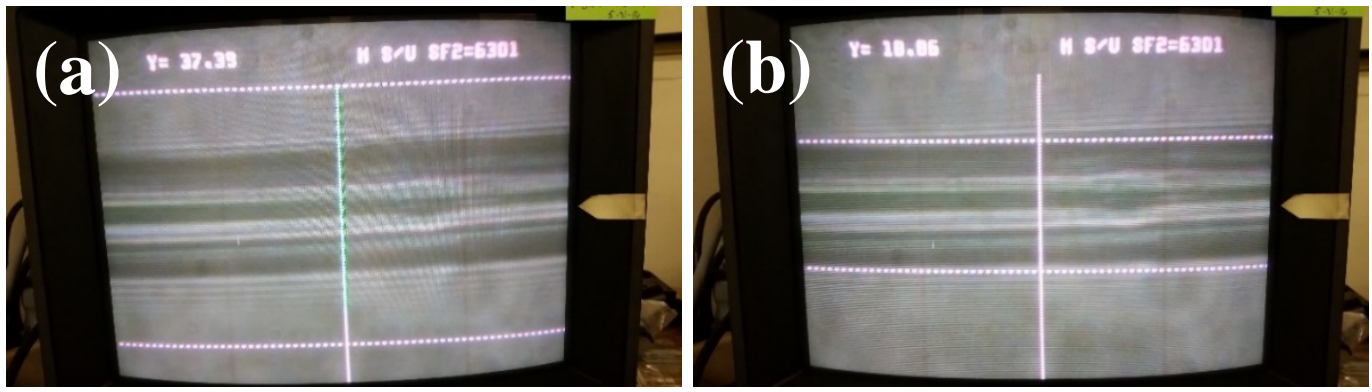

Fig. 7. (a) An image of the diameter measurement process with the fiber in focus before the horizontal graticule lines are moved. (b) A fiber diameter measurement showing the top of each horizontal graticule line touching an edge of the fiber.

\subsection{Tensile Testing Equipment}

\subsubsection{Single Fiber Heater}

A custom heater was designed and fabricated to heat single fiber specimens with a $10 \mathrm{~mm}$ gauge length to temperatures between room temperature and the melting temperature (nominally $150^{\circ} \mathrm{C}$ ). The design of the heater took into account the following requirements: the heater had to allow placement of gripped fibers into the heating channel, minimize difficulty in accessing the fiber channel to avoid post-test fiber damage, rapidly heat the fiber to minimize artificial annealing, provide accurate real-time temperature measurements of the fiber channel, maintain a consistent and symmetric thermal profile along the gauge length of the fiber, and maintain repeatable heating profiles between tensile tests.

The fiber heater was constructed from oxygen-free high thermal conductivity (OFHC) copper that was $88.9 \mathrm{~mm}$ (3.5 in) in length with a hexagonally shaped projection in the center, as shown in Fig. 8 (a). A thickness of $9.77 \mathrm{~mm}$ was chosen to allow for an air insulation layer between the heater surface and the grips for $10 \mathrm{~mm}$ gauge length samples. The copper heater was cut into two equal halves through the width dimension to allow the heater to be placed around the gripped fiber specimens. The fiber channel spans the thickness of the heater, is centered along the width and length of the heater, and has diameter of $1.016 \mathrm{~mm}(0.040 \mathrm{in})$. 20 W resistance cartridge heaters (Omega CSS-10120/120V) were selected. Two cartridge heaters are inserted into the top and bottom hexagonal projections and attached to a voltage controller to regulate the heat output. For real-time temperature measurements, small diameter thermocouples (Omega HTTC36-K-116G-2) are inserted in diagonally symmetric positions across the cut surface of the heater. Steel guide posts are located diagonally symmetric and opposite to the thermocouples to provide consistent alignment of the heater and to prevent contact with the fiber specimen when closing. Once the fiber sample is loaded, two socket capped machine screws are used to tighten the two heater halves together. The temperature is selected and allowed to stabilize before beginning the test. The open heater is shown in Fig. 8 (a). The diagonally opposed components and OFHC copper were selected with the goal of heating the fiber consistently. 

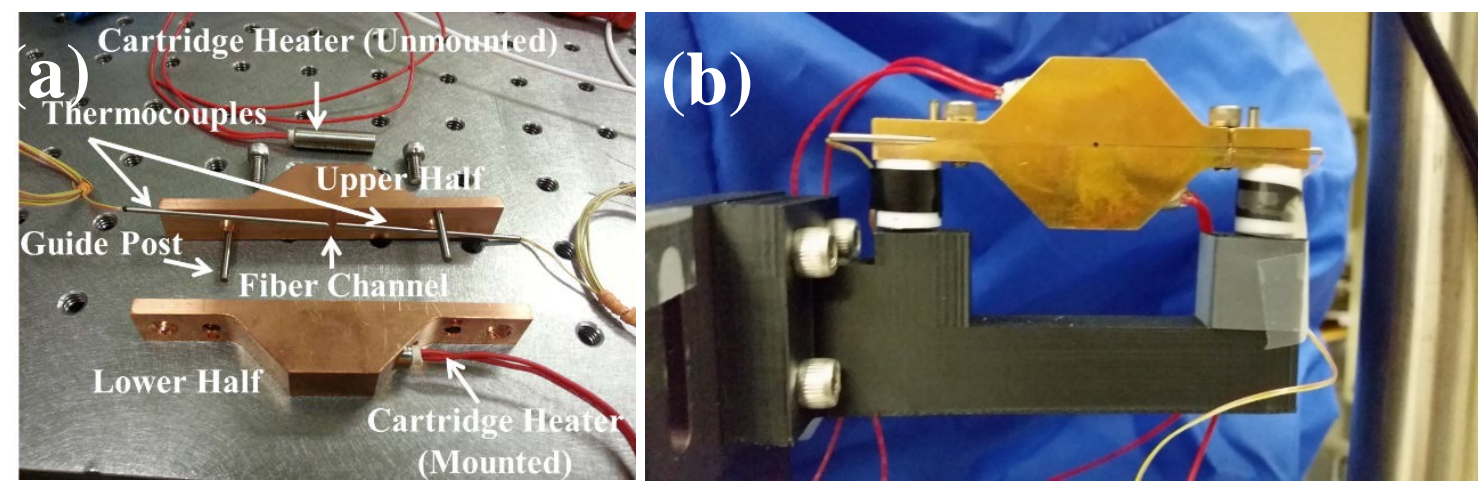

Fig. 8. (a) The single fiber heater in the open position. One cartridge heater is shown unmounted for reference. (b) The single fiber heater on the supporting stand with polytetrafluroethylene spacers.

A supporting stand for the fiber heater was 3D printed with acrylonitrilebutadiene styrene (ABS) plastic and connected to an $x-y-z$ translation stage to allow the lower half of the fiber heater to be moved away from the fiber gripping area. 12.5-mm-thick polytetrafluroethylene spacers are used to insulate the heater from the ABS stand, as shown in Fig. 8 (b). A base was also 3D printed with ABS plastic for the $x-y-z$ translation stage and to hold the electrical connections between the cartridge heaters and their voltage controller. The heater, stand, and base with translation stage will be referred to as the heater assembly.

The thermocouples in the heater assembly (the heater thermocouples) were thermally calibrated using a butt-welded small diameter $(0.125 \mathrm{~mm})$ wire thermocouple (Omega CHAL-005-BW). The wire and heater thermocouples were first calibrated at $0{ }^{\circ} \mathrm{C}$ in an ice bath using a dual channel digital thermometer (Omega HH12B) with a $0.1{ }^{\circ} \mathrm{C}$ resolution. The wire thermocouple was then glued to a U-shaped 3D printed ABS plastic mount which allowed the wire to be free-floating when placed into the fiber channel. The wirethermocouple mount was then attached to an $x-y-z$ translation stage and its thermocouple junction was positioned in the center of fiber channel. The calibration apparatus is shown in Fig. 9.
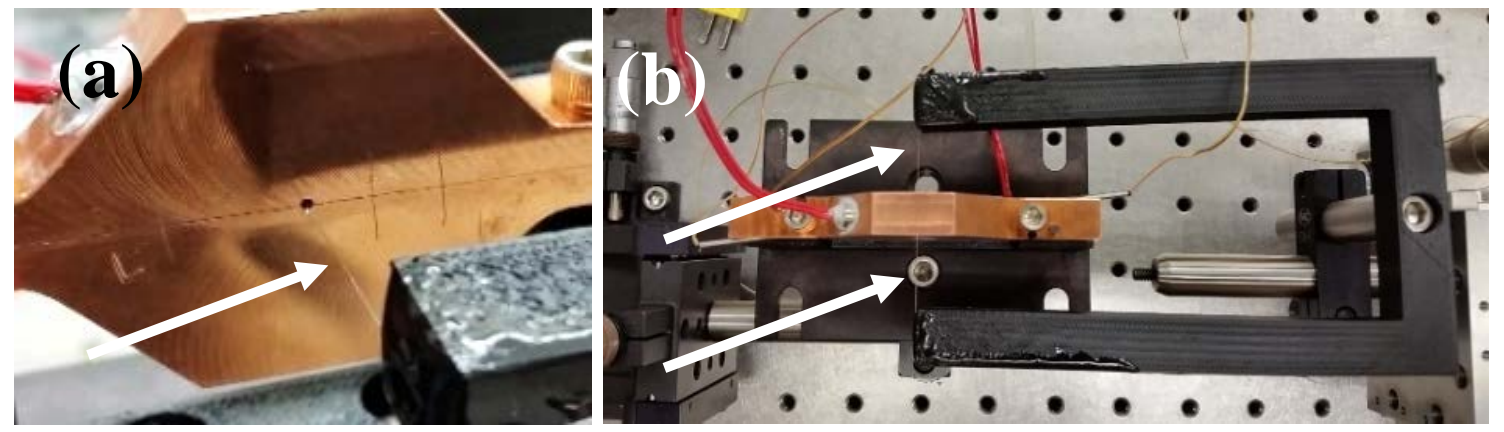

Fig. 9. (a) The closed single fiber heater with the calibration wire thermocouple installed in the fiber channel. (b) The top view of the setup displaying the U-shaped wire thermocouple mount and $x-y-z$ translation stage setups. White arrows indicate the thermocouple, and fiber grips are not installed in this photograph. 
The time-temperature response of the heater thermocouples was calibrated using the wire thermocouples and the following process. The voltage controller was set to $120 \mathrm{~V}$ and heating cycles were conducted for $240 \mathrm{~s}$ while measuring thermocouple temperatures every $5 \mathrm{~s}$. Between heating cycles, the heater was cooled to $20^{\circ} \mathrm{C}$ before the next cycle was started. An average of three cycles for each heater thermocouple were used to calculate timetemperature curves. Using these curves, the correction between the heater thermocouples and the fiber channel was determined for each temperature for the temperature-strain-rate experiments.

Next, the time-temperature profile of the fiber channel was measured. The wire thermocouple was translated in the $x, y$, and $z$ directions in the fiber channel and using the same heating protocol as previously described. Temperature measurements were taken along the two circular axes of the channel up to $0.15 \mathrm{~mm}$ from the center with a spacing of 0.05 $\mathrm{mm}$ in both the positive and the negative directions (six measurements along each axis and one in the center). The change in temperature between these locations and the center was found to be less than $2{ }^{\circ} \mathrm{C}$. In the long axis of the fiber channel, tests were conducted to a maximum of $5 \mathrm{~mm}$ with a spacing of $1 \mathrm{~mm}$. The change in temperature from the center for the long axis was less than $9{ }^{\circ} \mathrm{C}$. It must be noted that for these $x-y-z$ tests, the fiber channel was exposed to air whereas in the temperature-strain-rate experiments the fiber grips almost enclose the fiber channel (9.77 $\mathrm{mm}$ heater width for $10 \mathrm{~mm}$ fiber samples). The physical design of the grips prevented the $x-y-z$ tests from being conducted with the grips enclosing the fiber channel. Therefore, the $2{ }^{\circ} \mathrm{C}$ variation along the circular axes of the fiber channel and $9{ }^{\circ} \mathrm{C}$ difference along the long axis of the fiber channel are likely overestimations of the variation in temperature in the fiber channel when a gripped fiber specimen is in place.

\subsubsection{Fiber Grips}

Fiber grips were designed and fabricated to directly grip the UHMMPE single fiber specimens for uniaxial tensile testing. The following requirements were considered in designing the grips: the fiber grips must allow templated fiber specimens to be positioned and gripped, must minimize the length of fiber specimen that is outside the fiber heater, must minimize fiber damage from gripping, must allow for a repeatable gripping force between tests, must minimize difficulty in accessing the fiber channel to avoid post-test fiber damage, and must be impedance matched to the fiber-Split-Hopkinson Tension Bar (SHTB).

The improved fiber grip design used here (see Fig. 10) was based on grips used by Kim and Sanborn [9-11], where their grips consist of a base and a removable grip top that together sandwich the single fiber specimen. The gripping pressure is created by tightening two screws connecting the top and bottom halves. Plastic tabs are used on the top and bottom portions of the grips, and only the tabs contact the fiber. The new design used in this study modified Kim's and Sanborn's design by changing from the rectangular edge-recessed polycarbonate tabs to T-shaped plastic tabs that extend to the grip edge. This allows the gripping area to extend to the full length of the grip and minimizes the length of fiber specimen that is outside of the fiber heater. The length of the stem portion of the T-shape is also approximately $50 \%$ longer than the previous tabs (6.58 mm vs. $4.97 \mathrm{~mm}$ ) allowing a larger gripping area. Another difference in the design is the use of two diagonally opposed guide posts to assist in consistently aligning the top of the grip with the bottom and to keep the gripping pressure normal to the T-surface. This prevents sliding of the top grip from 
causing damage to the fiber specimen and also allows for easy opening of the grip for postfailure analysis of the fibers.

(a)

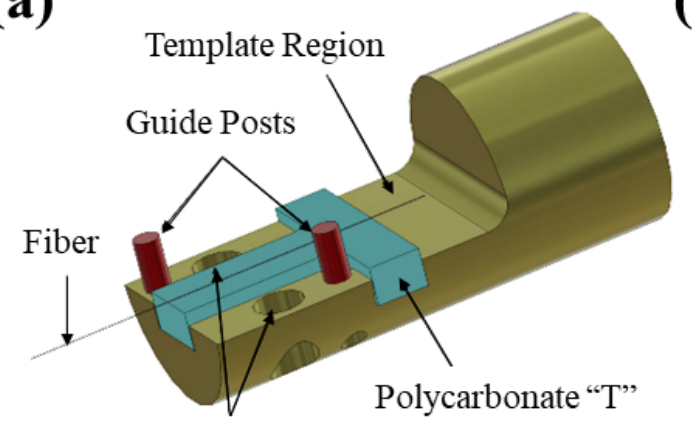

Threaded Screw

Holes (b)

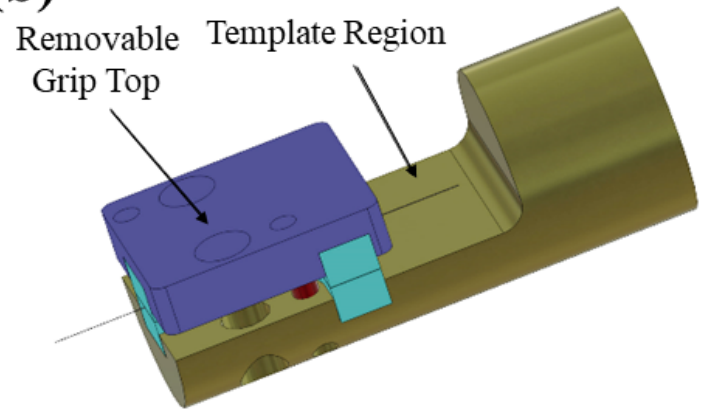

Fig. 10. Magnified schematics of (a) the grip bottom displaying the fiber, polycarbonate " $T$ ”, guide posts, screw holes, and template area, and (b) the closed grip showing the top in position without the 0-80 screws.

The gripping pressure is consistently applied by using an electric torque screwdriver to tighten two 0-80 steel screws. Tensile tests were conducted to determine the gripping torque that would maximize gripping while minimizing fiber damage. Fiber damage can induce failure at the interface of the grip edge and the fiber. A torque of about $0.0219 \mathrm{~N} \cdot \mathrm{m}$ was found to provide the best performance as shown by average tensile strength and average strain-to failure analyses. Equation (1) below is the formula for calculating downward force from an applied torque where $F$ is the downward force, $T$ is the applied torque, $c$ is the coefficient of friction of the threading, and $D$ is the screw outer diameter. Using parameters for steel 0-80 screws with an outer diameter of $1.524 \mathrm{~mm}$ and assuming a steel coefficient of friction of 0.2 , a downward force of approximately $71.9 \mathrm{~N}$ is applied in the grips.

$$
F=\frac{T}{c D}
$$

The choice of material for the main grip structure is also important. Mismatches in impedance can cause strain-wave reflections and can delay the peak load in the force sensor which causes a longer time-to-tensile failure. A longer failure time results in higher strain-tofailure values at constant strain-rate. Thus, to obtain the best data from the fiber-SHTB, the material used in the grips must be impedance matched to the material that comprises the SHTB. The existing SHTB was manufactured from aluminum (Al) 6061, therefore, Al 6061 was originally selected to be used for the grips. However, the machining process weakened the material to the extent that the aluminum threads stripped when tightening the steel screws. A new grip material was selected by again matching the strain-wave speed with the Al 6061 fiber-SHTB. The strain wave speed is given by:

$$
v_{s w}=\sqrt{\frac{E}{\rho}},
$$


where $v_{s w}$ is the strain wave speed, $E$ is the Young's modulus, and $\rho$ is the density. Stainless steel 303 proved to be a good match as its Young's modulus and density are both approximately three times that of $\mathrm{Al} \mathrm{6061.} \mathrm{A} \mathrm{second} \mathrm{set} \mathrm{of} \mathrm{grips} \mathrm{was} \mathrm{made} \mathrm{from} 303$ stainless steel. The 303 steel was not adversely affected by the machining process and retained its strength during screw tightening. The 303 steel grips were used for this study.

\subsection{Tensile Test Setup}

To ensure that the grips described above functioned well for a variety of temperatures and strain-rates, tensile tests were performed at temperatures ranging from room temperature to the melting temperature, and the strain-rates from quasi-static to dynamic. In particular, the temperatures were $20^{\circ} \mathrm{C}$, approximately room temperature; $75^{\circ} \mathrm{C}$, near the $\alpha$-relaxation temperature for polyethylene (a temperature region of interest where the molecular motion in the polymer is increased [12]); and $145^{\circ} \mathrm{C}$, which is slightly below the melting temperature $\left(\approx 150{ }^{\circ} \mathrm{C}\right)$. The three strain-rates selected were $10^{-3} \mathrm{~s}^{-1}, 10^{-1} \mathrm{~s}^{-1}$, and $500 \mathrm{~s}^{-1}$. Single fiber tensile test standards are given in ASTM C1557 and D3822 [13, 14], and these standards were adapted for these experiments.

\subsubsection{Low and Intermediate Strain-Rates}

A Bose Electroforce 3100 with $2.5 \mathrm{~mm}$ displacement and $22 \mathrm{~N}$ load cell was used to conduct uniaxial tensile tests on UHMMPE single fibers at low and intermediate strain-rates. This instrument is capable of testing fibers at strain-rates between $10^{-3} \mathrm{~s}^{-1}$ and $10^{0} \mathrm{~s}^{-1}$. With a set gauge length, $\ell$, the crosshead speed, $v_{\text {cross }}$, for the desired strain-rate, $R_{s}$, is determined as follows:

$$
v_{\text {cross }}=\ell R_{s} \text {. }
$$

A maximum displacement was programmed in the instrument software to be $2.49 \mathrm{~mm}$ (to prevent software error messages from appearing at the maximum displacement of the instrument). Data acquisitions were set to trigger on a displacement of $0.001 \mathrm{~mm} \pm 0.05 \%$ to capture the entire test in one scan. For the strain-rates presented here, the scan times were $200 \mathrm{~s}$ and $2 \mathrm{~s}$ for the $10^{-3} \mathrm{~s}^{-1}$, and $10^{-1} \mathrm{~s}^{-1}$ strain-rate tests, respectively. In the event of a false trigger, the automatic rdr file extension captured data for an extended timeframe of 64 total scans. There were 2048 data elements per scan. To reduce the noise in data acquisition, the load cell digital filter was set to $1000 \mathrm{~Hz}$, and $10 \mathrm{~Hz}$ for $10^{-3} \mathrm{~s}^{-1}$ and $10^{-1} \mathrm{~s}^{-1}$, respectively. Key test parameters for each strain-rate are listed in Table 1 . The recorded parameters for each tensile test were displacement in $\mathrm{mm}$ and load in $\mathrm{N}$.

Table 1. Key instrument test parameters for the Bose Electroforce 3100 Universal Testing Machine.

\begin{tabular}{ccccc}
\hline $\begin{array}{c}\text { Strain-rate } \\
{\left[\mathbf{s}^{-\mathbf{1}}\right]}\end{array}$ & $\begin{array}{c}\text { Crosshead } \\
\text { Displacement } \\
\text { Speed }[\mathbf{m m} / \mathbf{s}]\end{array}$ & $\begin{array}{c}\text { Scan Time } \\
{[\mathbf{s}]}\end{array}$ & $\begin{array}{c}\text { Data elements } \\
\text { per Scan }\end{array}$ & $\begin{array}{c}\text { Load Cell } \\
\text { Filter Digital } \\
{[\mathbf{H z}]}\end{array}$ \\
\hline $10^{-3}$ & 0.01 & 200 & 2048 & 1000 \\
$10^{-1}$ & 1 & 2 & 2048 & 10 \\
\hline
\end{tabular}


A ceramic thermal standoff was placed between the load cell and the grips to prevent thermal runoff from affecting the load measurement. A silicon carbide female-threaded cylindrical standoff about $38 \mathrm{~mm}$ (1.5 in) in length with a nominal $19 \mathrm{~mm}(0.75 \mathrm{in})$ outer diameter with 18-8 stainless steel screw thread adapters was used and is shown in Fig. 11.

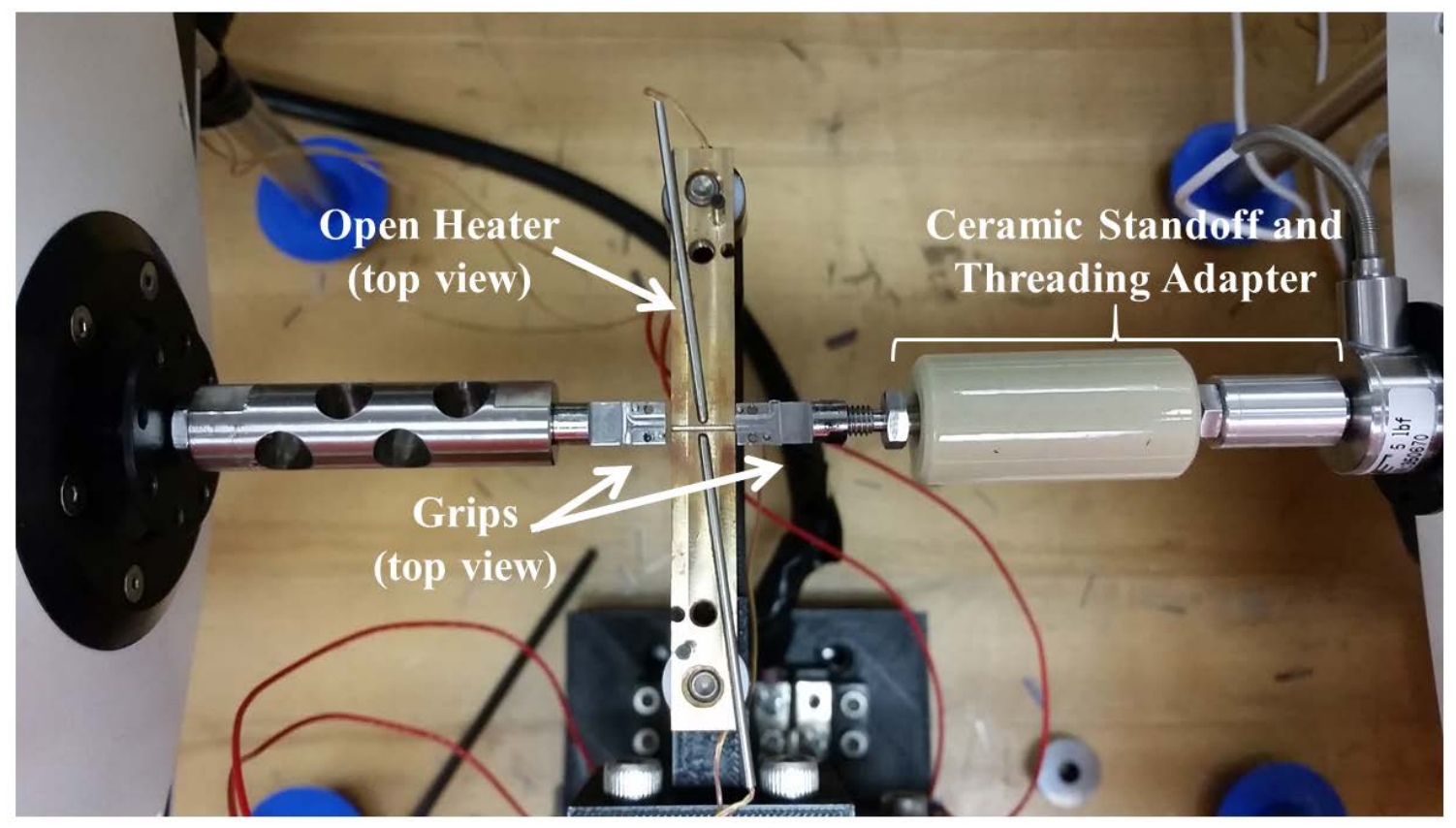

Fig. 11. The Bose 3100 fiber gripping area including grips, heater, standoff assembly, and force sensor.

For the fibers tested at temperatures greater than about $20^{\circ} \mathrm{C}$, the gauge length was set using a metal spacer, with a thickness of about $10.17 \mathrm{~mm}$, between the fiber grips. A gauge length of $10.17 \mathrm{~mm}$ was used to allow a nominal $0.2 \mathrm{~mm}$ air insulation layer on each side between the heater and the grips to minimize the heating of the grips and the load sensor, as pictured in Fig. 13. This position was set as the zero-displacement position and the instrument would return to this position for subsequent tensile tests. 


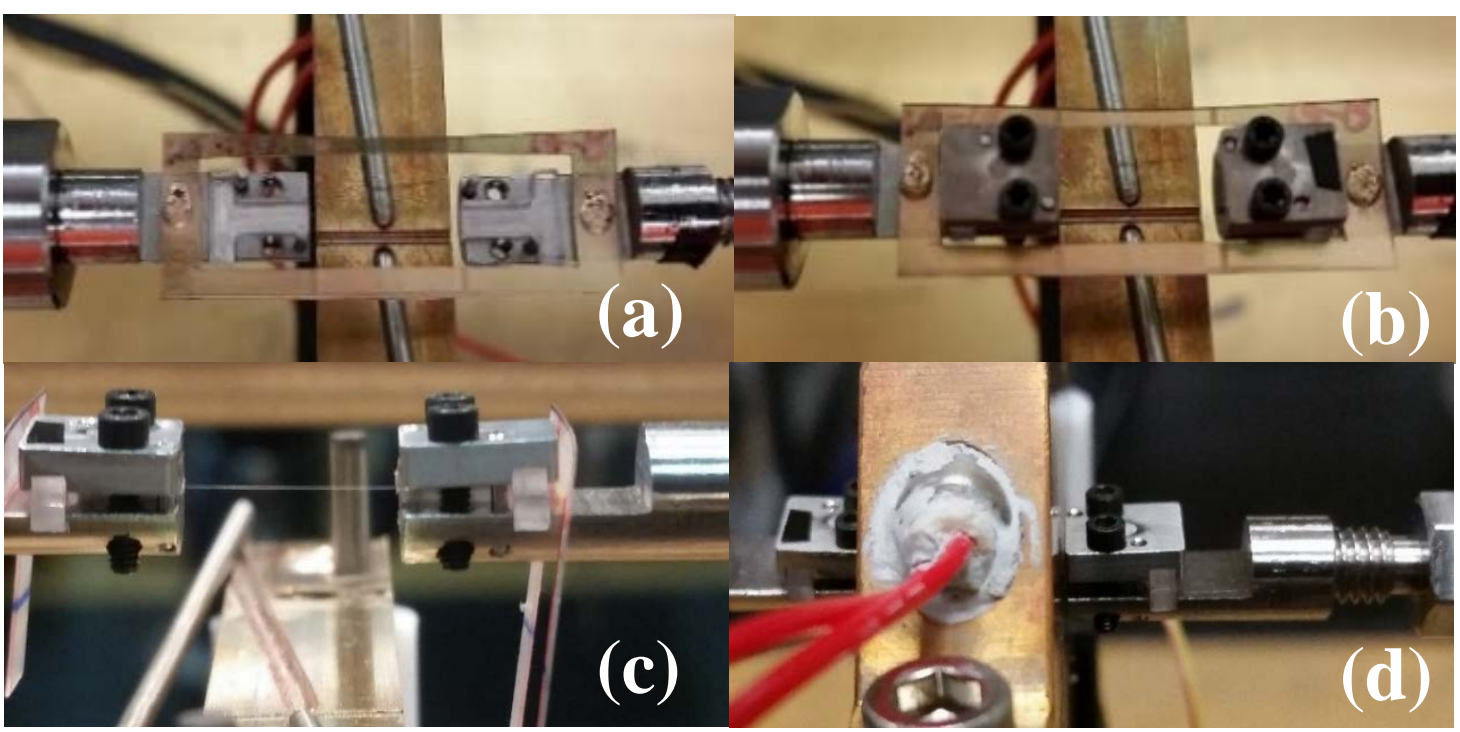

Fig. 12. (a) A templated fiber specimen placed on top of the open grips (removable grip tops not in place) and aligned. (b) A gripped fiber before the template is cut, with removable grip tops in place. (c) A gripped fiber with the template cut. (d) A fiber specimen gripped in the closed heater channel and ready for testing.

To load a fiber specimen for tensile testing, the fiber heater was opened, and the bottom half was lowered below the gripping area. The T-shaped polycarbonate portions of the grips were rinsed with ethanol and wiped with a cotton-tipped swab to remove any residue from the previous test. The grips were set to the zero-position (10.17 mm spacing). The templated fiber sample was then placed across the open grips, shown in Fig. 12 (a), and a Zeiss Stemi2000 Stereo Microscope with a 6.5X to 50X magnification range was used to aid in the centering and alignment of the fiber specimen. The upper grips were then placed on top of the fiber, see Fig. 12 (b), and tightened using a HIOS CL-2000 electric torque driver. The template was then cut on both sides in the area between the gauge length marker lines, shown in Fig. 12 (c). With the aid of the stereo microscope, the lower half of the heater was then raised so the fiber was halfway into the lower half of the fiber channel. The fiber was also translated to be in the center of the channel. The heater top was then placed on top of the fiber and the force sensor readout was monitored to determine if the fiber moved during this process. The heater screws were then hand-tightened to bring the two halves of the heater assembly into contact. The sample was then heated using the voltage controller. All samples were initially heated using the maximum setting on the heater and then was decreased to a steady state level to maintain the desired temperature. Once at temperature, the tensile test was started. The overall Bose 3100 testing area is shown in Fig. 13. 


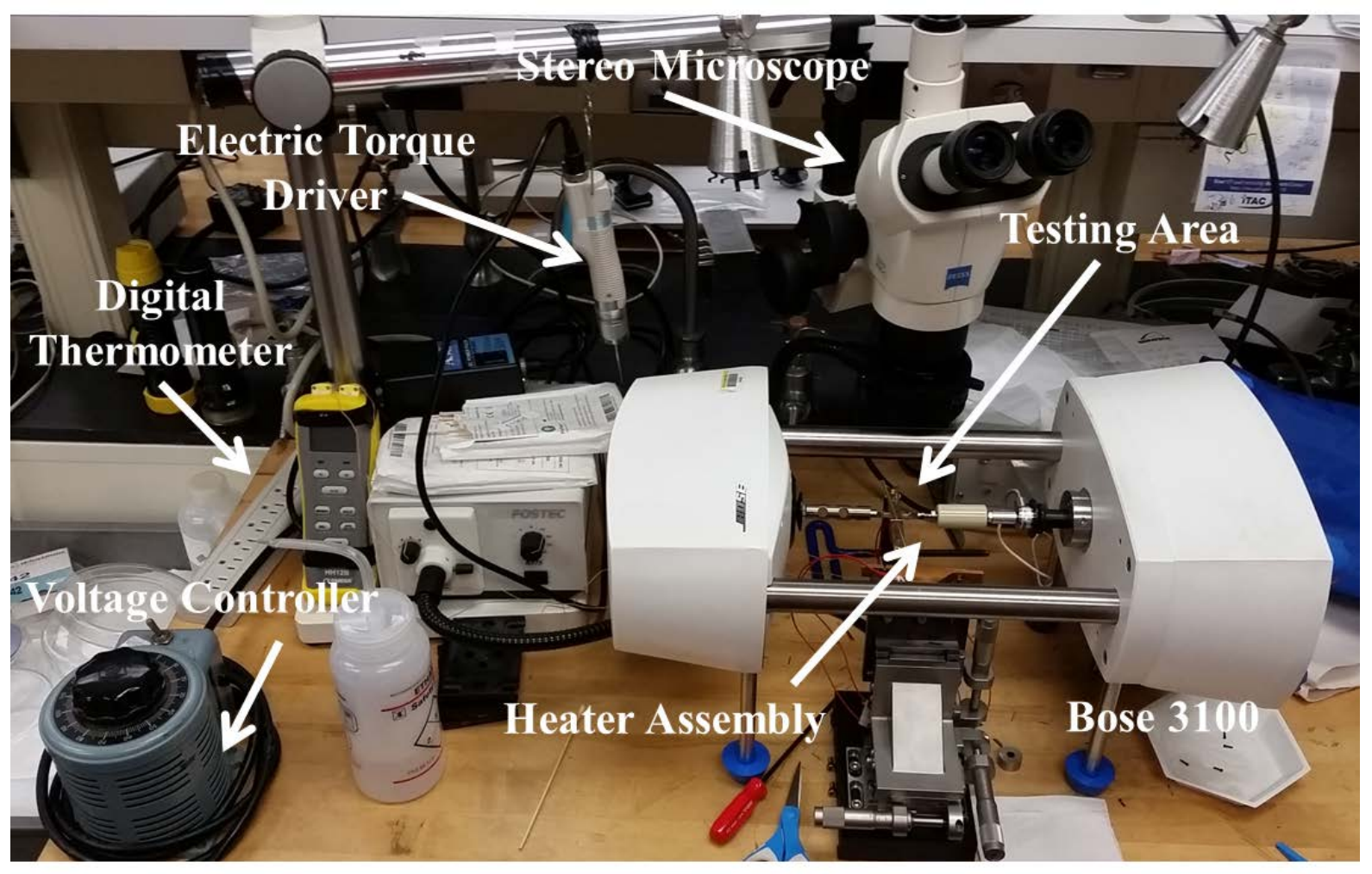

Fig. 13. The Bose 3100 fiber testing area including Bose 3100, testing area, stereo microscope, electric torque driver, heater assembly, digital thermometer and voltage controller.

\subsubsection{High Strain-Rates}

A fiber-Split-Hopkinson Tension Bar (SHTB) with a $22 \mathrm{~N}$ dynamic load cell was used to conduct uniaxial tensile tests on UHMMPE single fibers at high strain-rates. The instrument is located at Aberdeen Proving Ground in Maryland and was used in collaboration with the Weapons Research and Materials Directorate of the Army Research Laboratory. The instrument uses a gas-driven system to fire a brass striker tube into pulse shaper material located on a flange at the end of the incident bar [11], and can achieve average strain-rates of about $500 \mathrm{~s}^{-1}$ and $10^{3} \mathrm{~s}^{-1}$ with a nominal $10 \mathrm{~mm}$ gauge length. Fig 14 shows the testing setup for the fiber-SHTB. For the $500 \mathrm{~s}^{-1}$ strain-rate results presented here, a gas firing pressure of $137.9 \mathrm{kPa}$ with a standard deviation of $1.38 \mathrm{kPa}$, measured over 100 specimens, was used and a soft annealed $\mathrm{Cu}$ annulus made of eight nominally 0.1 -mm-thick $\mathrm{Cu}$ tapes was used as the pulse shaper. An optical system was used to measure displacement [9-11, 15]. The optical system was calibrated at least once per week by using a linear translation stage and a driving plate to move the tension bar by increments of approximately $0.051 \mathrm{~mm}$ while the optical sensor voltage was recorded. Linear fits were used to obtain the correlation between sensor voltage and displacement. The optical apparatus is shown in Fig. 14 and an example of a linear fitting is shown in Fig. 16. The optical system was calibrated multiple times over the course of this study. Each fiber tensile test was matched to the proper coefficient for calculated strain values. Two strain gauges were mounted half way down the bar on opposite sides and were attached to a Wheatstone bridge circuit including a variable resistor to set the bridge voltage to near zero before each tensile test, shown in Fig. 15. Data capture was 
triggered off the strain gauge voltage when it exceeded $150 \mathrm{mV}$ for more than $25 \mu \mathrm{s}$. The dynamic load cell was calibrated to approximately $3.5 \mathrm{~N} / \mathrm{mV}$ and was connected to a Kistler 5010 Dual Mode Amplifier, which converts the load cell output voltage into newtons. An HBM Genesis High Speed GEN7t Transient Recorder and Data Acquisition System with Differential Input Card and Perception software was used to collect simultaneous time [s], strain gauge Wheatstone bridge voltage [V], optical displacement voltage [V], and load [N]. To prevent heating of the load cell, the ceramic thermal standoff assembly was also used with fiber-SHTB as shown in Fig. 15. The dynamic load cell has a female socket for attaching a grip. The tightening of the thermal standoff assembly, the lever-arm force from the weight of the thermal assembly, and the propagation of dynamic strain wave during these experiments caused the thermal standoff to impart an artificial bias to the load measurements. The bias was corrected by conducting 10 tensile tests at room temperature with and without the thermal assembly. This correction procedure was performed each time the thermal standoff was initially attached or tightened.

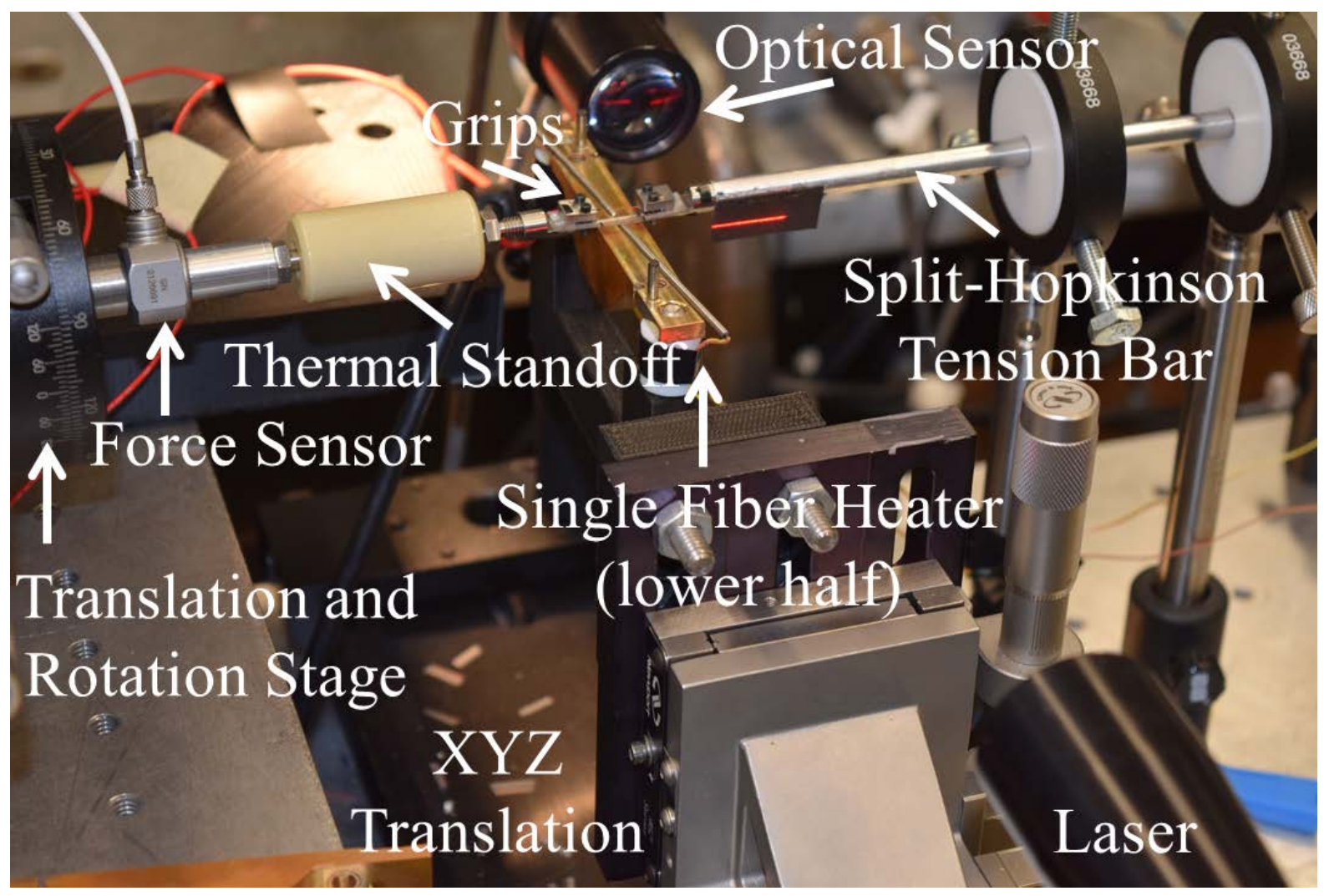

Fig. 14. An image of the testing area of the fiber-SHTB showing the measurement devices including the piezoelectric load cell, thermal standoff assembly, closed grips with fiber sample, heater bottom half, and optical setup for measuring displacement. 


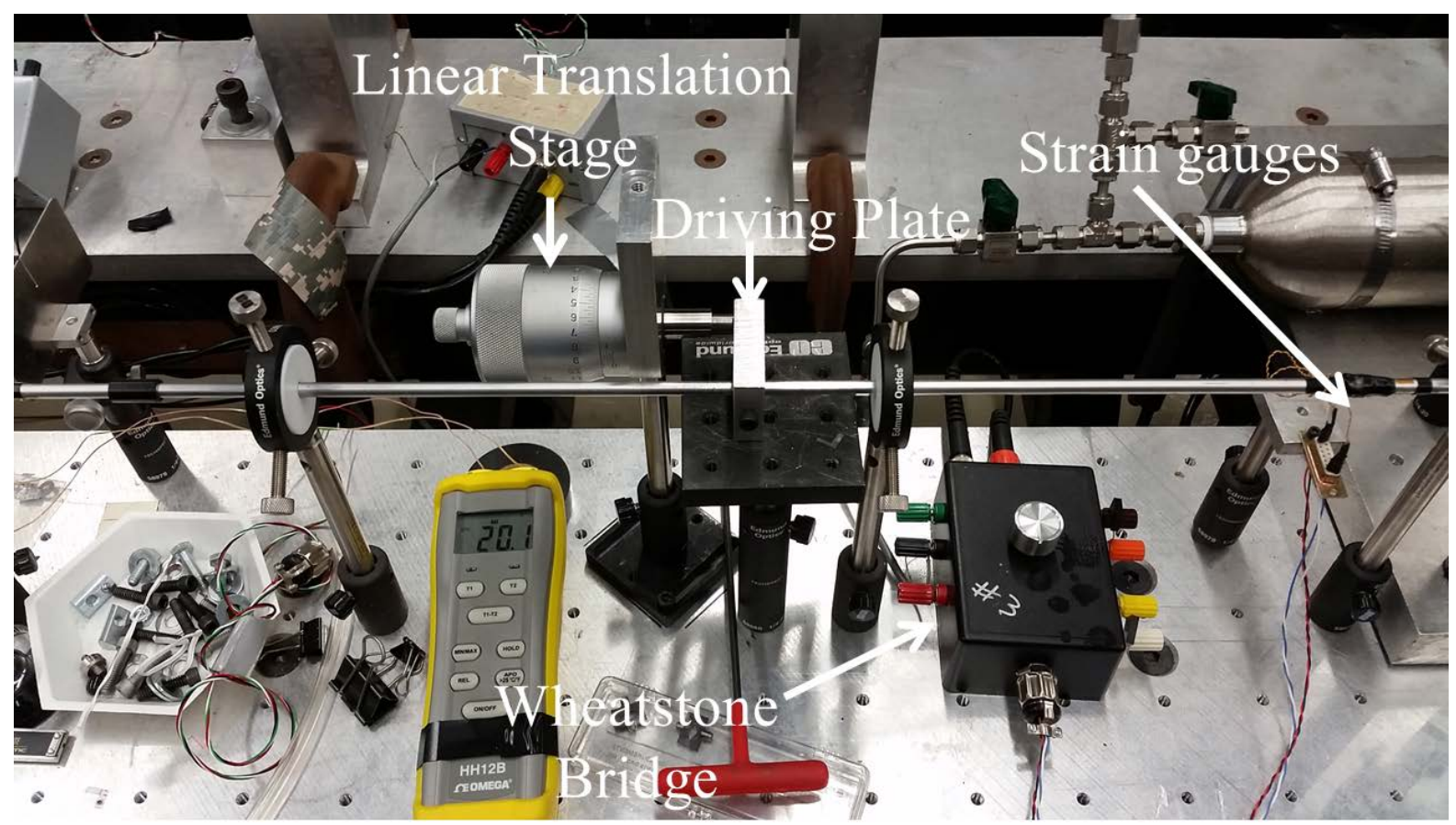

Fig. 15. The displacement calibration setup showing the linear translation stage and driving plate. Also shown in this image are the strain gauges and Wheatstone bridge with variable resistor.

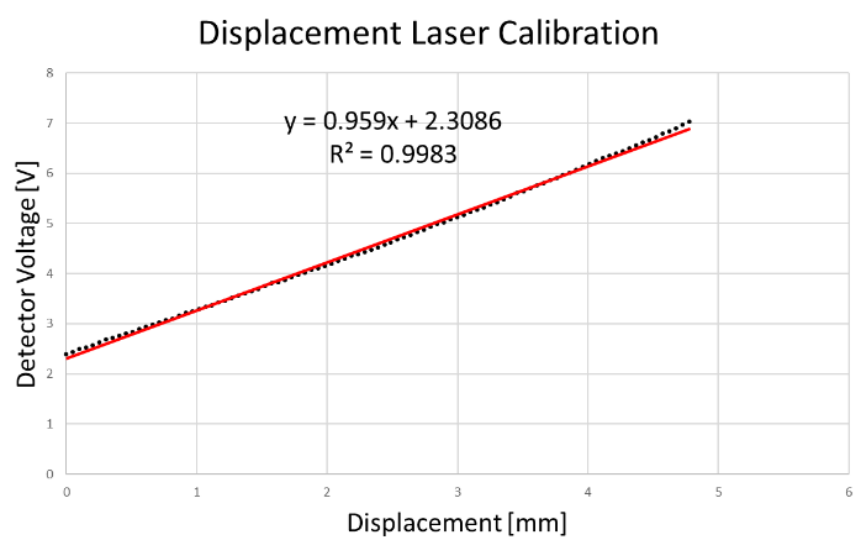

Fig. 16. An example of the linear fitting of a voltage-displacement data. The black dots are the measured data and the red line is the linear fit. The line equation and $\mathrm{R}^{2}$ values are also displayed. 


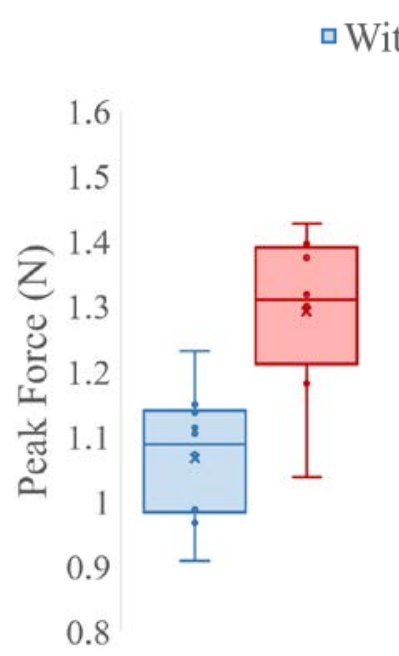

(a)

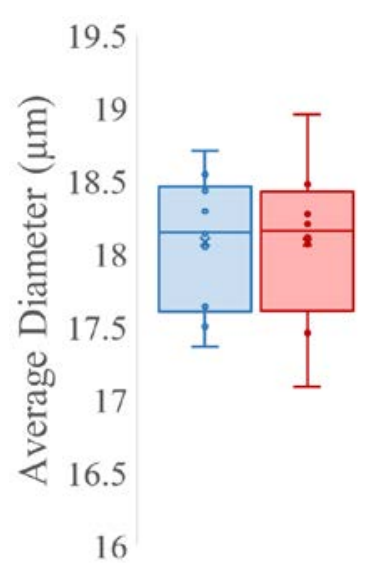

(b)

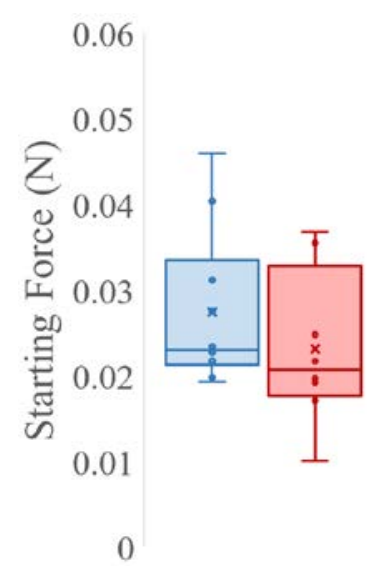

(c)

Fig. 17. Whisker plots for the correction showing a comparison between (a) peak force, (b) average fiber diameter, and (c) the pre-tension force or starting force. In a whisker plot the ends of the box are the upper and lower quartiles, while the whiskers extend to the extreme values.

For the correction using a $500 \mathrm{~s}^{-1}$ strain-rate, the average force difference between the two sets of 10 samples was about $0.226 \mathrm{~N}(0.0508 \mathrm{lbf})$. Two factors that can affect the failure force of a fiber specimen are the individual fiber diameter and the pre-tension force from the specimen preparation and gripping procedures. To determine if either influenced the change in force values between the sets of specimens with and without the thermal standoff assembly, each individual average diameter and the pre-tension force for each fiber specimen in the two sets were compared and are shown as whisker plots in Fig. 17. Student's t-tests were conducted to test the null hypothesis for the average differences between peak force, average fiber diameter, and pre-tension force. Probabilities of about 0.0012, 0.99, and 0.33 were found, respectively. Using a rejection criterion of $5 \%$, the tests indicate that there is a statistical difference in peak force but not in the average fiber diameter and starting force. The t-tests for this correction at $500 \mathrm{~s}^{-1}$ are summarized in Table 2. A force correction of $0.226 \mathrm{~N}$ was applied to the samples tested with this correction.

Table 2. The summary of the Student's t-tests for the correction experiments at $500 \mathrm{~s}^{-1}$. The total number of tests considered is 10 .

\begin{tabular}{ccccccc}
\hline & \multicolumn{2}{c}{$\begin{array}{c}\text { Peak Force } \\
\text { [N] }\end{array}$} & \multicolumn{2}{c}{$\begin{array}{c}\text { Average Diameter } \\
\text { [ } \mathbf{m m ]}\end{array}$} & \multicolumn{2}{c}{$\begin{array}{c}\text { Starting Force } \\
\text { [N] }\end{array}$} \\
& Without & With & Without & With & Without & With \\
\hline Mean & 1.07 & 1.29 & 18.08 & 18.08 & 0.027 & 0.023 \\
Variance & 0.01 & 0.02 & 0.2 & 0.3 & $8 \mathrm{E}-05$ & $8 \mathrm{E}-05$ \\
$\quad \mathbf{N}$ & 10 & 8 & 10 & 8 & 10 & 8 \\
$\begin{array}{c}\mathbf{P} \text { (vs. } \\
\text { without) }\end{array}$ & N/A & 0.001219 & N/A & 0.9939 & N/A & 0.3353 \\
\hline
\end{tabular}




\section{Selected Results}

Force-displacement data from 59 tensile tests were used to calculate fiber mechanical properties for demonstrating the efficacy of new testing method. Constant strain-rate to failure tensile tests were conducted on commercially available UHMMPE 1760 dtex single fibers at 9 combinations of 3 temperatures from room temperature to the melting temperature $\left(20^{\circ} \mathrm{C}\right.$ to $\left.145^{\circ} \mathrm{C}\right)$ and 3 strain-rates from quasi-static to dynamic $\left(10^{-3} \mathrm{~s}^{-1}\right.$ to $\left.500 \mathrm{~s}^{-1}\right)$. Throughout this report, the term strain refers to compliance corrected engineering strain and the term stress refers to engineering stress calculated using the average diameter of the fiber specimen unless otherwise stated. The compliance corrected strain values were calculated according to ASTM C1557-03 [13] using $0.1186 \mathrm{~mm} / \mathrm{N}$ for the $10^{-3} \mathrm{~s}^{-1}$, and $10^{-1} \mathrm{~s}^{-1}$ strainrates, and $0.0692 \mathrm{~mm} / \mathrm{N}$ for the $500 \mathrm{~s}^{-1}$ strain-rate.

\subsection{Categorization and Number of Fiber Tests}

Before tensile testing, 144 each 10-mm-gauge-length fiber specimens were dedicated for non-tensile purposes including grip torque testing, temperature range selection for the tensile tests, and determination of instrument capture settings including data collection rates, load cell digital filters, and trigger parameters. Stress-strain data may not have been recorded for these tests. For the tensile results presented here, 59 separate 10-mm-gauge-length fiber specimens were prepared.

The target number of tensile tests across the temperature-strain-rate study was 60 . This includes 5 specimens per temperature-strain-rate combination for the quasi-static and intermediate strain-rates, and 10 specimens per combination for the dynamic strain-rate. Of the 60 tensile tests attempted, only one fiber specimen was broken during the grip-loading procedure.

Table 3. The number of fibers tests, failures at the grip interface (given in parentheses), and non-failures (given on the left of a slash) in each testing combination for the temperaturestrain-rate tensile study. A total of 59 fiber specimens were tested in this study. The highlighted region depicts the non-failure surface.

\begin{tabular}{ccccc}
\hline $\begin{array}{c}\text { Strain-rate } \\
{\left[\mathbf{s}^{-1}\right]}\end{array}$ & $\mathbf{2 0}{ }^{\circ} \mathbf{C}$ & $\mathbf{7 5}^{\circ} \mathbf{C}$ & $\mathbf{1 4 5}^{\circ} \mathbf{C}$ & Total \\
\hline $10^{-3}$ & $4(1)$ & $1 / 4$ & $0 / 5$ & 15 \\
$10^{-1}$ & 5 & 5 & $0 / 5$ & 15 \\
500 & $9(1)$ & 10 & 9 & 29 \\
Total & 20 & 20 & 19 & 59 \\
\hline
\end{tabular}

Table 3 summarizes the number of specimens that failed in the gauge area, failed at the edge of the grips, and that did not fail. For example, a 4 (1) indicates that there are five total fiber specimens in that temperature-strain-rate combination and one of them was observed to fail at the fiber interface, while $1 / 4$ indicates that there are five fiber specimens total, one failed, and four were non-failures. The highlighted step-like shape illustrates that as strain-rate is 
increased, the corresponding temperature where non-failures begins increases as well, which will be described further in a future publication.

\subsection{Percentage of failures in gauge region}

The main metric for gauging grip performance is the percentage of tensile failures in the gauge length of the fiber. The total number of failures at the grip interface across the temperatures and strain-rates conducted in this study was two, making the success of a tensile failure occurring within the gauge length approximately $96.6 \%$, or $95.6 \%$ when excluding fibers that did not fail. The distribution by strain-rate of the percentage of successful tests is summarized in Table 4. However, the two failures at the grip interface had failure strength values above the average failure strength for that temperature-strain-rate combination indicating that the grip did not affect the fiber behavior. Thus, the data for these two samples were included when calculating the averages for their temperature-strain-rate combination.

Table 4. The number of grip interface failures observed for the 59 tensile tests, categorized by strain-rate. The last row shows the overall success if the non-failures are removed from the calculations.

\begin{tabular}{cccc}
\hline $\begin{array}{c}\text { Strain-rate } \\
{\left[\mathbf{s}^{-\mathbf{1}}\right]}\end{array}$ & $\begin{array}{c}\text { Number of } \\
\text { Fiber } \\
\text { Samples }\end{array}$ & $\begin{array}{c}\text { Breaks at } \\
\text { Grip } \\
\text { Interface }\end{array}$ & $\begin{array}{c}\text { \% Breaks in } \\
\text { Gauge } \\
\text { Length }\end{array}$ \\
\hline $\mathbf{1 0}^{-3}$ & 15 & 1 & 93 \\
$\mathbf{1 0}^{-1}$ & 15 & 0 & 100 \\
$\mathbf{5 0 0}$ & 29 & 1 & 97 \\
Total(Including non-failures) & 59 & 2 & 97 \\
Total & 45 & 2 & 96 \\
(Excluding non-failures) & & & \\
\hline
\end{tabular}

This report focuses on the results for three strain-rates and three temperature combinations, however six strain-rates and nine temperatures were explored for the purposes of a complete study. All data that comprises these results will not be presented here. The intermediate and dynamic strain-rates result in more failures at the interface than at the high strain-rate.

The observed average ultimate tensile stress (UTS) value decreases as temperature increases for a given strain-rate, signifying that the grip experiences less overall force before fiber failure. $20^{\circ} \mathrm{C}$ is the lowest temperature utilized in this study and exhibited the highest average UTS values. To demonstrate the gripping success rate, data at $20^{\circ} \mathrm{C}$ and all six strain-rates is analyzed. The number of specimens for the quasi-static and intermediate strainrates at $20^{\circ} \mathrm{C}$ is only five specimens per strain-rate and 10 specimens per strain-rate for the dynamic strain-rate. To remedy the low number of tests, the fibers that were used for determining setup parameters (non-tensile purposes) are used to expand the population size for the determination of success rates. While stress and strain information were not recorded for these fibers, the failure location was. Considering all six strain-rates at $20^{\circ} \mathrm{C}$, the overall success rate of failures in the gauge length is approximately $82.35 \%$. Columns 2 to 4 in Table 5 shows the distribution of the $20^{\circ} \mathrm{C}$ data by strain-rate for the three strain-rates presented here. Also shown are the success rates of Sanborn, et al. [11] in column 7. Table 5 
shows that the grips used in this study outperformed their grips at $10^{-3} \mathrm{~s}^{-1}$, and performed much better at dynamic strain-rates. Reasons for this trend will be explored in a future paper.

Table 5. The number of grip interface failures and success rates observed for the $20{ }^{\circ} \mathrm{C}$ data set including retests and fibers used for non-tensile purposes. The $5^{\text {th }}$ and $6^{\text {th }}$ columns show the number and success rates if the higher than average failure strength fibers are removed from the calculations. The last column shows the grip success rates for Sanborn, et al. [11] for strain-rates conducted in their study.

\begin{tabular}{|c|c|c|c|c|c|c|}
\hline $\begin{array}{c}\text { Strain- } \\
\text { rate } \\
{\left[\mathbf{s}^{-1}\right]}\end{array}$ & $\begin{array}{c}\begin{array}{c}\text { Number } \\
\text { of } \\
\text { Fiber }\end{array} \\
\text { Samples }\end{array}$ & $\begin{array}{c}\text { Breaks at } \\
\text { Grip } \\
\text { Interface }\end{array}$ & $\begin{array}{c}\text { \% Breaks } \\
\text { in } \\
\text { Gauge } \\
\text { Length }\end{array}$ & $\begin{array}{c}\text { Breaks at } \\
\text { Grip } \\
\text { Excluding } \\
\text { High } \\
\text { Failure } \\
\text { Strength } \\
\text { Samples }\end{array}$ & $\begin{array}{c}\text { \% Breaks } \\
\text { in Gauge } \\
\text { Length } \\
\text { Excluding } \\
\text { High } \\
\text { Failure } \\
\text { Strength } \\
\text { Samples }\end{array}$ & $\begin{array}{c}\text { \% Breaks } \\
\text { in } \\
\text { Gauge } \\
\text { Length by } \\
\text { Sanborn, } \\
\text { et al. }\end{array}$ \\
\hline $10^{-3}$ & 28 & 1 & 96 & 0 & 100 & 90 \\
\hline $10^{-1}$ & 8 & 0 & 100 & 0 & 100 & - \\
\hline 500 & 22 & 6 & 72 & 5 & 78 & - \\
\hline 775 & - & - & - & - & - & 42 \\
\hline
\end{tabular}

\subsection{Strain to Failure}

The average strain to failure values are also used as a metric for the evaluation of the custom grips used in this study. The values can be compared to other corrected strain to failure values to determine if the custom grips are performing without a significant level of continuous slippage within the grip. The only comparable grip study in the literature comes from Sanborn, et al. who conducted their study at room temperature. Table 6 shows the comparison of corrected strain to failure values for their room temperature and 3 strain-rates and the $20^{\circ} \mathrm{C}$ data and 3 strain-rates from this study and indicates lower average corrected strain to failure values at comparable strain-rates in quasi-static testing. Comparing the 500 $\mathrm{s}^{-1}$ strain-rate with the $775 \mathrm{~s}^{-1}$, note that the failure strain for the $500 \mathrm{~s}^{-1}$ rate is somewhat higher.

Table 6. Comparison of the uncorrected and corrected average strain to failure values and associated standard deviations observed in this study at $20^{\circ} \mathrm{C}$ and those by Sanborn, et al. [11]. Sandborn's experiments utilized 10 specimens per strain rate. The number of specimens used in our study can be found in Table 3.

\begin{tabular}{ccccc}
\hline $\begin{array}{c}\text { Strain-rate } \\
{\left[\mathbf{s}^{-1}\right]}\end{array}$ & $\begin{array}{c}\text { Uncorrected } \\
\text { Strain-to- } \\
\text { failure, this } \\
\text { study } \\
{[\%]}\end{array}$ & $\begin{array}{c}\text { Uncorrected } \\
\text { Strain-to- } \\
\text { failure } \\
\text { Sanborn, et al. }\end{array}$ & $\begin{array}{c}\text { Corrected } \\
\text { Strain-to- } \\
\text { failure, this } \\
\text { study } \\
{[\%]}\end{array}$ & $\begin{array}{c}\text { Corrected } \\
\text { Strain-to- } \\
\text { failure } \\
\text { Sanborn, et al. } \\
\text { [\%] }\end{array}$ \\
\hline $10^{-3}$ & $4.43 \pm 0.18$ & $5.53 \pm 0.87$ & $3.38 \pm 0.17$ & $3.93 \pm 0.96$ \\
$10^{-1}$ & $4.20 \pm 0.06$ & - & $3.03 \pm 0.24$ & -
\end{tabular}




\begin{tabular}{ccccc}
\hline $\begin{array}{c}\text { Strain-rate } \\
{\left[\mathbf{s}^{-1}\right]}\end{array}$ & $\begin{array}{c}\text { Uncorrected } \\
\text { Strain-to- } \\
\text { failure, this } \\
\text { study } \\
{[\%]}\end{array}$ & $\begin{array}{c}\text { Uncorrected } \\
\text { Strain-to- } \\
\text { failure } \\
\text { Sanborn, et al. } \\
{[\%]}\end{array}$ & $\begin{array}{c}\text { Corrected } \\
\text { Strain-to- } \\
\text { failure, this } \\
\text { study } \\
{[\%]}\end{array}$ & $\begin{array}{c}\text { Corrected } \\
\text { Strain-to- } \\
\text { failure } \\
\text { Sanborn, et al. } \\
{[\%]}\end{array}$ \\
\hline $10^{0}$ & - & $4.83 \pm 0.72$ & - & $3.35 \pm 0.25$ \\
500 & $3.98 \pm 0.71$ & - & $3.25 \pm 0.70$ & - \\
775 & - & $3.71 \pm 0.26$ & - & $3.00 \pm 0.24$ \\
\hline
\end{tabular}

The average strains to failure for the various test conditions were validated from experimentation as shown in Table. 7. The differences in the experimental values observed here will be discussed as part of a future publication.

Table 7. Average strain to failure values with \pm one standard deviation, with the number of specimens given in Table 3. The highlighted region indicates non-failure behavior. The $10^{-3} \mathrm{~s}^{-}$ ${ }^{1}$ strain-rate at $75{ }^{\circ} \mathrm{C}$ resulted in only one of the five tensile tests failing and therefore lacks a standard deviation.

\begin{tabular}{cccc}
\hline Strain-rate [s-1] & $\mathbf{2 0}^{\circ} \mathbf{C}$ & $\mathbf{7 5}{ }^{\circ} \mathbf{C}$ & $\mathbf{1 4 5}{ }^{\circ} \mathbf{C}$ \\
\hline $10^{-3}$ & $3.38 \pm 0.17$ & 24.11 & \\
$10^{-1}$ & $3.03 \pm 0.24$ & $3.70 \pm 0.02$ & \\
500 & $3.25 \pm 0.70$ & $2.99 \pm 0.33$ & $2.85 \pm 0.55$ \\
\hline
\end{tabular}

\section{Grip Performance}

As previously discussed, gripping UHMMPE single fibers is challenging. The T-shaped design of the custom grips used in this study allowed for a heater to be placed over the entire fiber gauge length and also allowed for a longer area for the fiber to be gripped as compared to previous studies [9-11, 15]. The performance of the custom grips used in this study was demonstrated by the success rate of failures in the gauge length and the values of compliance corrected strain. The number of grip failures was greatly reduced from those given in previous reports (Sanborn, et al. [11]). At the $500 \mathrm{~s}^{-1}$ strain-rate, previous reports had $42 \%$ breaks in the gauge length (non-grip breaks) whereas for this study it was approximately 78 $\%$. The other metric of success for the grips was the average corrected strain to failure values. A value close to or lower than previous studies indicates the there is little to no slippage in the grips during a tensile test. The observed average corrected strain to failure values were lower than others reported (Sanborn, et al. [11]) for the quasi-static and intermediate strainrates but slightly higher for the dynamic strain-rate. One possible explanation for the higher average strain to failure values at the dynamic strain-rates is strain-wave reflections within the thermal standoff apparatus. The standoff was inserted between the grip and the load cell and the reflections are caused by the change in material and cross-sectional area within the thermal standoff. These changes occurred at each material change from the grip to steel thread adapters to the ceramic thermal insulator to another steel thread adapter. These 
mismatches in impedance cause strain wave reflections and can delay the peak load in the force sensor which causes a longer failure time. A longer failure time results in higher strain to failure values at constant strain-rate. To verify this, the fibers used for the force correction did not use the thermal standoff. The average corrected strain to failure for the 10 specimens at $10^{3} \mathrm{~s}^{-1}$ was 0.0280 with a standard deviation of 0.0027 which is lower than previous reports (Sanborn, et al. [11]) at dynamic strain-rates. Another possibility is the interpretation of the unstable region of the stress-strain curve. The stress-strain plots of Sanborn, et al. [11] did not discuss an unstable region near failure. It is possible that the authors interpreted the beginning of the unstable region as the point of fiber failure and would therefore have lower strain to failure values. Additionally, Sanborn, et al. conducted their tests at a higher dynamic strain-rate of $775 \mathrm{~s}^{-1}$ which is higher than the $500 \mathrm{~s}^{-1}$ strain-rate used in this study. This behavior will be investigated in a future paper.

\section{Conclusion}

The challenge of gripping single fiber UHMMPE fibers for determination of mechanical properties was addressed by the development of a novel grip design. This design improved upon existing grip designs for UHMMPE by making it easier to load and manipulate specimens, and also allowed for the incorporation of a fiber heater to investigate thermal effects. The custom-designed grips were verified to perform well at all strain-rates and allowed the observation of strain measurements across the $20^{\circ} \mathrm{C}$ to $145^{\circ} \mathrm{C}$ temperature range and strain-rates from quasi-static $\left(10^{-3} \mathrm{~s}^{-1}\right)$ to dynamic $\left(500 \mathrm{~s}^{-1}\right)$. The strain to failure values for the dynamic strain-rates may be slightly overestimated due to the strain-wave reflections in the thermal standoff. However, the relative changes in strain to failure across the temperature range can still be compared for trends. This report is focused primarily on presenting the details of the experimental procedures and apparatus. A further discussion of the results of these experiments are the subject of a future publication.

\section{Acknowledgments}

The authors would like to gratefully acknowledge the U.S. Army Research Laboratory in Aberdeen, MD for allowing us to use their Split-Hopkinson Tension Bar facility for the experiments described herein. We would specifically like to acknowledge Tusit Weerasooriya (ARL) and C. Allan Gunnarson for their assistance with the fiber-SHTB experiments and data interpretation. We would also like to thank Richard Allen (NIST) for allowing us to use the Bose instrument for the quasistatic tests, and Rusty Hettenhouser and Jay Brandenberg for assistance in designing and fabricating the fiber grips and heater.

\section{References}

[1] Termonia Y, Smith P (1987) Kinetic-Model for Tensile Deformation of Polymers .1. Effect of Molecular-Weight. Macromolecules 20(4):835-838. Available at \%3CGo

[2] Lin SP, Han JL, Yeh JT, Chang FC, Hsieh KH (2007) Surface Modification and Physical Properties of Various UHMWPE-Fiber-Reinforced Modified Epoxy Composites. Journal of Applied Polymer Science 104:655-665.

[3] Umberger PD (2010) Characterization and Response of Thermoplastic Composites and Constituents. thesis (Virginia Polytechnic Institute and State University). Available at 
https://vtechworks.lib.vt.edu/bitstream/handle/10919/33574/Umberger_PD_T_2010.p df?sequence $=2$ \&isAllowed $=y$

[4] Russell BP, Karthikeyan K, Deshpande VS, Fleck NA (2013) The high strain rate response of Ultra High Molecular-weight Polyethylene: From fibre to laminate.

International Journal of Impact Engineering 60:1-9. https://doi.org/10.1016/j.ijimpeng.2013.03.010

[5] Hild DN, Schwartz P (1992) Plasma-treated ultra-high strength polyethylene fibers. Part II. Increased adhesion to poly(methyl methacrylate). Journal of Adhesion Science and Technology 6(8):897-917. https://doi.org/10.1163/156856192X00520

[6] Schwartz P, Netravali A, Sembach S (1986) Effects of strain rate and gauge length on the failure of ultra-high strength polyethylene fibers. Textile research journal.

Available at http://trj.sagepub.com/content/56/8/502.short

[7] Hudspeth M, Nie X, Chen W (2012) Dynamic failure of Dyneema SK76 single fibers under biaxial shear/tension. Polymer. https://doi.org/10.1016/j.polymer.2012.09.020

[8] Chocron S, Pintor A, Rosello C, Cendon D, Sanchez-Galvez V (2002) Characterization of Fraglight Non-Woven Felt and Simulation of FSP's Impact in It. Available at http://stinet.dtic.mil/oai/oai?\&verb=getRecord\&metadataPrefix=html\&identifier=AD A389410

[9] Kim JH, Alan Heckert N, Leigh SD, Rhorer RL, Kobayashi H, McDonough WG, Rice KD, Holmes GA (2014) Statistical analysis of PPTA fiber strengths measured under high strain rate condition. Composites Science and Technology 98:93-99. https://doi.org/10.1016/j.compscitech.2012.03.021

[10] Kim JH, Heckert NA, Leigh SD, Kobayashi H, McDonough WG, Rice KD, Holmes GA (2013) Effects of fiber gripping methods on the single fiber tensile test: I. Nonparametric statistical analysis. Journal of Materials Science 48(10):3623-3637. https://doi.org/10.1007/s10853-013-7142-y

[11] Sanborn B, DiLeonardi AM, Weerasooriya T (2014) Tensile Properties of Dyneema SK76 Single Fibers at Multiple Loading Rates Using a Direct Gripping Method. ARLTR-6974 (Aberdeen, MD). https://doi.org/10.1007/s40870-014-0001-3

[12] Litvinov VM, Xu J, Melian C, Demco DE, Möller M, Simmelink J (2011) Morphology, chain dynamics, and domain sizes in highly drawn gel-spun ultrahigh molecular weight polyethylene fibers at the final stages of drawing by SAXS, WAXS, and 1H Solid-State NMR. Macromolecules 44(23):9254-9266. https://doi.org/10.1021/ma201888f

[13] Semiautomatic U, Analysis AI (2014) ASTM C1557-14 Standard Test Method for Tensile Strength and Young's Modulus of Fibers (ASTM International). https://doi.org/10.1520/C1557-14.2

[14] ASTM D3822/D3822M-14 (2015) Standard Test Method for Tensile Properties of Single Textile Fibers. ASTM International, USA (June):1-10. https://doi.org/10.1520/D3822

[15] Sanborn B, DiLeonardi AM, Weerasooriya T (2015) Tensile Properties of Dyneema SK76 Single Fibers at Multiple Loading Rates Using a Direct Gripping Method. Journal of Dynamic Behavior of Materials 1(1):4-14. https://doi.org/10.1007/s40870014-0001-3 